Article

\title{
The Response of Cupriavidus Metallidurans CH34 to Cadmium Involves a Decrease in Intracellular Levels of C-Di-GMP Probably Mediated by a Novel Metal Regulated Phosphodiesterase That Inhibits the Biofilm Lifestyle
}

\author{
Pablo Alviz-Gazitua 1,2,3, Sebastián Fuentes ${ }^{4}$, Luis Rojas ${ }^{2,5}$, Raymond J. Turner ${ }^{6}$, Michael Seeger ${ }^{2, *}$ \\ and Nicolás Guiliani ${ }^{1, *}$ \\ 1. Bacterial Communication Laboratory, Biology Department, Faculty of Sciences, Universidad de Chile, \\ Ñuñoa, Santiago, Chile. alviz.pablo@gmail.com \\ 2. Molecular Microbiology and Environmental Biotechnology Laboratory, Chemistry Department \& Center \\ of Biotechnology, Universidad Técnica Federico Santa María, Valparaíso, Chile. \\ 3. PhD program of Microbiology, Faculty of Sciences, Universidad de Chile, Nuñoa, Santiago, Chile. \\ 4. Microbial Ecology of Extreme Systems Laboratory, Biological Sciences Faculty, Pontificia Universidad \\ Católica de Chile, Santiago, Chile. \\ 5. Chemistry Department, Universidad Católica del Norte, Avenida Angamos 0610, Antofagasta CL- \\ 1240000, Chile \\ 6. Biofilm Research Group, Department of Biological Sciences, University of Calgary, Calgary, Canada. \\ * Correspondence: michael.seeger@gmail.com, michael.seeger@usm.cl; Tel.: +56-322654223 \& nguilian@uchile.cl; \\ Tel.: +56-229787241. These authors contributed equally to this work.
}

\begin{abstract}
Cadmium is a highly toxic heavy metal for biological systems. Cupriavidus metallidurans $\mathrm{CH} 34$ is a model strain for heavy metal resistance and bioremediation. The aim of this study was to determine the role of the c-di-GMP pathway in the $\mathrm{C}$. metallidurans $\mathrm{CH} 34$ response to cadmium in both planktonic and biofilm cells. Increasing cadmium concentrations correlates with an inhibition of biofilm formation and EPS production in C. metallidurans cells. Planktonic and biofilm cells showed similar tolerance to cadmium. During exposure to cadmium an acute decrease of c-di-GMP levels in planktonic and biofilm cells was observed. Transcription analysis by RT-qPCR showed that cadmium induced in planktonic cells and strongly induced in biofilm cells the expression of the urf2 gene and the mercuric reductase encoding mer $A$ gene, which belong to the Tn501/Tn21 mer operon. After exposure to cadmium the cad $A$ gene involved in cadmium resistance was equally upregulated in both lifestyles. Bioinformatic analysis and null mutant complementation assays indicated that the protein encoded by the urf 2 gene is a functional phosphodiesterase involved in the c-di-GMP metabolism. We propose to rename the urf 2 gene as mrp gene for metal regulated phosphodiesterase. An increase of the second messenger c-diGMP content by the heterologous expression of the constitutively active diguanylate cyclase PleD* correlated with an increase in biofilm formation and cadmium susceptibility. These results indicate that the response to cadmium in C. metallidurans $\mathrm{CH} 34$ involves a decrease in c-di-GMP content that inhibits the biofilm lifestyle.
\end{abstract}

Keywords: c-di-GMP; Cupriavidus metallidurans; cadmium; phosphodiesterase; biofilm; urf2 gene; mer gene; PleD. 
2 of 42

\section{Introduction}

Cadmium is a highly toxic heavy metal for biological systems. Cadmium induces indirectly oxidative stress, disturbs manganese acquisition and depletes the cellular reduced thiols pool [1-3]. This heavy metal is also carcinogenic [4]. Global cadmium production has risen $>1,000$ fold in the last century due to its incorporation to diverse manufacture applications [1]. The Word Health Organization has included cadmium in the top ten of the "Chemicals of major Public Health concern" list [4].

The remediation of heavy metals in polluted waters and soils is a major challenge for sustainable development. Microorganisms are used to immobilize and/or transform heavy metals into less toxic forms $[5,6]$. Heavy metal bioremediation strategies are commonly carried out in fixed bed reactors wherein the formation of attached multicellular communities - i.e. biofilm - is crucial. Biofilm cells produce extracellular polymeric substances (EPS) such as polysaccharides, lipids, proteins and extracellular DNA, providing different functional groups that may bind heavy metal ions via passive biosorption processes that immobilize heavy metals and protect cells [7]. Biofilms are also involved in bioreduction processes trough electrically conductive components [8-10]. Biofilms has been described as an advantageous lifestyle promoted by toxic heavy metals or compounds, which allow the selection of resistant cells [7]. However, in contrast to the bacterial response to antibiotics, planktonic and biofilm cells are in most cases almost equally susceptible to heavy metal oxyanions and cations [8,11]. Consequently, the minimum biofilm-eradication concentration (MBEC) is often not higher than the minimum bactericidal concentration (MBC) observed under planktonic growth conditions. Specific bacterial biofilms are even more susceptible to oxyanions than planktonic cells. The effect of the heavy metals on biofilm depend on the bacterial strain, the metal and the culture medium [11-13].

Biofilm formation in response to environmental conditions is mediated by the second messenger bis-(3'-5')-cyclic dimeric guanosine monophosphate (c-di-GMP) [14]. Intracellular cdi-GMP content depends on the balance between the enzymatic activities of diguanylate cyclases (DGCs) and phosphodiesterases (PDEs) that catalyze the formation and the degradation of c-di-GMP, respectively. DGC activity depends on the characteristic protein domain GGDEF [15], whereas PDE activity is mediated by the two motifs EAL and HD-GYP $[16,17]$. In addition to the catalytic motifs, DGCs and PDEs contain accessory motifs responsible for the regulation of the activity under different conditions. At high intracellular c-di-GMP content, it interacts with a broad spectra of c-di-GMP binding effectors that can be riboswitches and a wide diversity of proteins. The effectors include degenerate GGDEF/EAL domain proteins [18,19] and PilZ domain proteins [20]. The c-di-GMP binding with effectors triggers a reduction of cell motility and an increase of EPS matrix synthesis, which promote biofilm formation $[18,19,21]$. However, the link between the c-di-GMP signaling pathway, bacterial lifestyle and heavy metal tolerance has not been explored.

Cupravidus metallidurans $\mathrm{CH} 34$ is a model heavy metal-resistant bacterium that has been used for bioremediation, recovery and reduction of heavy metals [22-24]. C. metallidurans $\mathrm{CH} 34$ 
harbors numerous heavy metal resistance mechanisms, including complexation, efflux systems, reduction and reductive precipitation, which enable cell detoxification and survival [25-27]. A high number of $\mathrm{CH} 34$ genes confer tolerance to high concentrations of heavy metals, including cadmium [25]. Nevertheless, molecular mechanisms driving the bacterial lifestyle in presence of heavy metals have not been studied. The aim of this study was to determine the role of the c-di-GMP pathway in the C. metallidurans $\mathrm{CH} 34$ response to cadmium in both planktonic and biofilm cells.

\section{Materials and Methods}

\subsection{Organisms, plasmids and growth conditions}

Bacterial strains and plasmids used in this study are listed in Table 1. C. metallidurans strains were cultured in low phosphate Tris-buffered mineral salts (LPTMS) broth (Tris $6.06 \mathrm{~g} \mathrm{~L}^{-1}, \mathrm{NaCl}$ $4.68 \mathrm{~g} \mathrm{~L}^{-1}, \mathrm{NH}_{4} \mathrm{Cl} 1.07 \mathrm{~g} \mathrm{~L}^{-1}, \mathrm{KCl} 1.49 \mathrm{~g} \mathrm{~L}^{-1}, \mathrm{Na}_{2} \mathrm{SO}_{4} \cdot 10 \mathrm{H}_{2} \mathrm{O} 0.98 \mathrm{~g} \mathrm{~L}^{-1}, \mathrm{MgCl}_{2} 6 \mathrm{H}_{2} \mathrm{O} 0.2 \mathrm{~g} \mathrm{~L}^{-1}, \mathrm{CaCl}_{2}$ - $2 \mathrm{H}_{2} 00.03 \mathrm{~g} \mathrm{~L}^{-1}, \mathrm{Na}_{2} \mathrm{HPO}_{4} 0.085 \mathrm{~g} \mathrm{~L}^{-1}, \mathrm{Fe}(\mathrm{III})\left(\mathrm{NH}_{4}\right)$ citrate $0.005 \mathrm{~g} \mathrm{~L}^{-1}$, succinate $0.3 \%$, and $1 \mathrm{~mL}$ $\mathrm{L}^{-1}$ of SL7 trace solution of Biebl and Pfennig [22]). Escherichia coli and Pseudomonas aeruginosa strains were cultured in LB broth (yeast extract $5 \mathrm{~g} \mathrm{~L}^{-1}$, peptone $10 \mathrm{~g} \mathrm{~L}^{-1}, \mathrm{NaCl} 5 \mathrm{~g} \mathrm{~L}^{-1}$ ). Plasmids pJB3Tc19 and pJB:pleD* [28] were donated by Juan San Juan research group (EEZ-CSIC, Granada, Spain).

\subsection{Biofilm formation assay}

C. metallidurans $\mathrm{CH} 34$ cell attachment in cadmium presence was assessed by an adapted protocol developed to monitor initial stages of biofilm formation [29]. Briefly, a stationary culture in LPTMS broth at $30^{\circ} \mathrm{C}$ and $150 \mathrm{rpm}$ was centrifuged and the cells were suspended in fresh LPTMS broth to an optical density at $600 \mathrm{~nm}$ of 1.0. This culture was distributed into a 96well microtiter plate by placing $200 \mu \mathrm{L}$ per well. A concentrated cadmium solution was further added to reach different concentrations. After $15 \mathrm{~h}$ of incubation at $30^{\circ} \mathrm{C}$ in static condition, planktonic cells were removed. Wells were washed with sterile distilled water and the biofilm adhered to the bottom was stained with crystal violet $(200 \mu \mathrm{L}$ per well, $0.1 \%$ solution for 15 $\mathrm{min})$. Plate was air-dried for $16 \mathrm{~h}$ and the stained biomass was suspended in $200 \mu \mathrm{L}$ of acetic acid 30\%. Absorbance of this suspension was measured either at 550 or $595 \mathrm{~nm}$. This value was normalized by the OD600 of the planktonic fraction removed previously. Viability of the each planktonic cell fraction was quantified by serial dilution and plating by triplicate on tryptic soy agar (15 $\mathrm{g} \mathrm{L}^{-1}$ pancreatic digest of casein, $5 \mathrm{~g} \mathrm{~L}^{-1}$ peptic digest of soybean meal, $5 \mathrm{~g} \mathrm{~L}^{-1}$ sodium chloride, $15 \mathrm{~g} \mathrm{~L}^{-1}$ agar), where the colony forming units (CFU) were counted.

Table 1. Plasmids and strains used in this study

\begin{tabular}{ccc}
\hline Plasmids & Description & Reference \\
\hline pJBTc19 & Ap $^{\mathrm{r}}, \mathrm{Tc}^{\mathrm{r}}$; expression vector & {$[28]$}
\end{tabular}




\begin{tabular}{|c|c|c|}
\hline pJBTc19:urf2.2 & $\begin{array}{c}\mathrm{Ap}^{\mathrm{r}}, \mathrm{Tc}^{\mathrm{r}} ; \mathrm{pJBTc} 19 \text { derivate bearing a } 1423 \mathrm{bp} \text { XbaI/EcoRI fragment } \\
\text { containing RMET_RS31035 }\end{array}$ & This work \\
\hline pJBTc19:pleD* & $\begin{array}{l}\mathrm{Ap}^{\mathrm{r}}, \mathrm{Tc}^{\mathrm{r}} ; \mathrm{pJBTc} 19 \text { derivate bearing a } 1423 \mathrm{bp} \mathrm{XbaI/EcoRI} \mathrm{fragment} \\
\text { containing pleD* }\end{array}$ & [28] \\
\hline Strains & Description & Reference \\
\hline C. metallidurans $\mathrm{CH} 34$ & Heavy metal multiresistant strain & [22] \\
\hline CH34 pJBTc19 & CH34 strain transformed with an empty vector & This work \\
\hline СH34 pJBTc19:urf2.2 & CH34 strain transformed with pJBTc19:urf2.2 construct & This work \\
\hline CH34 pJBTc19:pleD* & CH34 strain transformed with pJBTc19:pleD* construct & This work \\
\hline P. aeruginosa PAO1 & Opportunistic pathogen & [30] \\
\hline$\Delta$ rocR pJBTc19 & rocR null mutant PAO1 strain transformed with pJBTc19 & This work \\
\hline$\Delta r o c R$ pJBTc19:urf2.2 & rocR null mutant PAO1 strain transformed with pJBTc19:urf2.2 & This work \\
\hline
\end{tabular}

\subsection{Qualitative assay for extracellular polymeric substances}

The assessment of cadmium effect on EPS synthesis by C. metallidurans CH34 macrocolonies was carried out in salt free LB agar with Congo Red $50 \mu \mathrm{g} \mathrm{mL}^{-1}$ and Coomassie Blue $10 \mu \mathrm{g} \mathrm{mL} \mathrm{m}^{-1}$ [31]. Plates were incubated for five days at room temperature and visualized with an Olympus MVX10 lens.

\subsection{Analysis of biofilm and planktonic lifestyles of C. metallidurans $\mathrm{CH} 34$}

For comparisons between biofilm and planktonic lifestyles, two aliquots of an LPTMS broth culture $\left(10^{8}\right.$ cells $\left.\mathrm{mL}^{-1}\right)$ were taken in parallel. For biofilm growth, $1 \mathrm{~mL}$ was vacuum filtered through a $0.2-\mu \mathrm{m}$ polycarbonate filter (Whatman) and the filter was placed on LPTMS agar 0.8 $\%$ with the cell filtrate facing upwards. The second 1-mL aliquot was inoculated into $9 \mathrm{~mL}$ of fresh LPTMS broth for planktonic growth. Both were incubated at $30{ }^{\circ} \mathrm{C}$, without shaking and at $150 \mathrm{rpm}$, respectively. This procedure synchronized both lifestyles cultures starting from the same growth phase and biomass. After $13 \mathrm{~h}$ at $30^{\circ} \mathrm{C}$, cultures were exposed to $2 \mathrm{mM}$ cadmium (Figure S1), either by translating the filter to a new LPTMS agar with cadmium (biofilm cells) or by directly adding a cadmium concentrated solution (planktonic cells). After 45 min incubation in presence of cadmium, cells were processed for c-di-GMP determination or qRTPCR.

\subsection{Extraction and quantification of c-di-GMP}

After incubation in presence or absence of cadmium, 9 of the $10 \mathrm{~mL}$ of planktonic culture were collected, leaving $1 \mathrm{~mL}$ for total protein content determination. To discard sample processing bias, biofilm cells were suspended in a mixture of $10 \mathrm{~mL}$ of LPTMS, separating a 1$\mathrm{mL}$ aliquot for total protein content determination. Cells in suspension were collected by centrifugation at $1,920 \times \mathrm{g}$ for $10 \mathrm{~min}$ at $4{ }^{\circ} \mathrm{C}$. As suggested by the quantification service provider, pellets were suspended in $300 \mu \mathrm{L}$ of extraction buffer (acetonitrile:methanol:water, 
2:2:1) into 2-mL micro tube vials and incubated $10 \mathrm{~min}$ at $95^{\circ} \mathrm{C}$ followed by cooling on ice. Cells lysates were centrifuged at $16,000 \mathrm{x}$ for $10 \mathrm{~min}$ at $4{ }^{\circ} \mathrm{C}$ and supernatants were transferred into new microtube vials. Extractions were repeteated twice omiting the heat incubation step. Combined supernatants of 3 extraction steps (about $700 \mu \mathrm{L}$ ) were stored at $-20{ }^{\circ} \mathrm{C}$ overnight. Prepitation of remaining cellular debris was made by centrifugation at $16,000 \times \mathrm{g}$ for $10 \mathrm{~min}$ at $4{ }^{\circ} \mathrm{C}$. Finally, supernatants were evaporated to dryness in Speed-Vac at room temperature. Nucleotide extraction from planktonic cells of $P$. aeruginosa strains followed the same procedure.

Quantification of c-di-GMP was achieved by liquid chromatography coupled to tandem mass spectrometry (LC-MS/MS) at BIOLOG Life-Sciences Institute (Bremen, Germany).

\subsection{Susceptibility Tests in Calgary Biofilm Device}

C. metallidurans cultures in the Calgary Biofilm Device were performed according to indications elsewhere specified [32]. Briefly, colonies grown in LPTMS agar during $48 \mathrm{~h}$ incubation at $30{ }^{\circ} \mathrm{C}$ were suspended in $\mathrm{NaCl} 0.9 \%$ to reach a turbidity equivalent to McFarland standard 1.0 (Thermo R20421). The suspension was diluted 15 times in LPTMS broth, loaded into the Calgary Biofilm Device (Innovotech) and incubated for $24 \mathrm{~h}$ at $150 \mathrm{rpm}$ and $30{ }^{\circ} \mathrm{C}$. Biofilms adhered to the lid pegs were separated from the planktonic fraction that stayed into the well. Cadmium susceptibility was determined by CFU counting in tryptic soy agar. MBC and MBEC were defined as the cadmium concentration killing $99.9 \%$ of the original population [7], starting from the fitted exponential decay curve achieved by non-linear regression in Prism v.5 (GraphPad software, San Diego-CA, USA). Determinations were carried out in two independent experiments, each in triplicate.

2.7 Functional prediction of genes encoding DGCs, PDEs and PilZ domain effectors in C. metallidurans CH34 genome

A list of genes coding for diguanylate cyclases (DGCs) and phosphodiesterases (PDEs) in C. metallidurans $\mathrm{CH} 34$ genome were retrieved from the NCBI website http://www.ncbi.nlm.nih.gov/Complete_Genomes/c-di-GMP.html, according to NCBI annotations. GGDEF, EAL and HD-GYP domain proteins coding genes were analysed. The catalytic functionality of each protein was evaluated by analyzing the conservation of the active amino acid residues in domain sequence motifs: residues Asp327, Lys332, Asn335, Asp344, Asp370, Lys442 and Arg446 for GGDEF; residues Glu523, Arg527, Glu546, Asn584, Glu616, Asp646, Asp647, Glu703 and Gln723 for EAL, and residues His183, Asp184, His212, His237, Glu (His)238, Asn(Glu)265, Asn (Arg)269 for HD-GYP, using as reference functional domains from PleD (GGDEF) of Caulobacter crescentus [15], TBD_1265 (EAL) of Thiobacillus denitrificans [16] and Bd1817 (HD-GYP) from Bdellovibrio bacteriovorus [17], respectively.

The c-di-GMP binding capability of the PilZ domains of C. metallidurans $\mathrm{CH} 34$ was predicted based on the conservation of the "c-di-GMP switch" (RxxxR \& D/NzSxxG), which undergoes the conformational change that wraps the c-di-GMP molecule [20]. The PilZ domain 
6 of 42

that integrates PA4608 of P. aeruginosa was used as active form model [21], whereas the PilZ domain present in XC1028 of Xanthomonas campestris was used as inactive form reference [33]. The search of c-di-GMP effectors related to Burkholderia cenocepacia Bcam1349 [34] and P. aeruginosa PelD in C. metallidurans $\mathrm{CH} 34$ genome was assessed by local alignment tools and pairwise sequence alignment.

Motif conservation in GGDEF and EAL domains was determined by multiple alignments in Clustal W [35], whereas motif conservation in PilZ domain was determined in multiple alignment by MAFFT method [36]. Motif conservation was visualized using Jalview software (http://www.jalview.org). Orthology inference was achieved through sequence similarity searching using BlastP algorithm [37] and confirmed by conservation of domains architectures obtained from NCBI's CDART tool [38].

\subsection{RNA extraction and reverse transcription}

After incubation of cells in presence or absence of cadmium, $10 \mathrm{~mL}$ planktonic culture was mixed with $2 \mathrm{~mL}$ "stop solution" (water-saturated phenol $5 \%(\mathrm{pH}<7.0)$, ethanol 95\%) [39,40]. To discard sample processing bias, biofilm cells were suspended in a mixture of $10 \mathrm{~mL}$ LPTMS and $2 \mathrm{~mL}$ stop solution. For both samples, cells were then collected by centrifugation at 1,920 $\mathrm{x}$ $\mathrm{g}$ for $10 \mathrm{~min}$ at $4{ }^{\circ} \mathrm{C}$ and suspended in $700 \mu \mathrm{L}$ of lysis buffer (sodium acetate $20 \mathrm{mM}$, EDTA 1 $\mathrm{mM}$, SDS $0.5 \%$, $\beta$-mercaptoethanol 1\%, $\mathrm{pH} 5.5$ ) and incubated $5 \mathrm{~min}$ at room temperature. Preheated acid phenol $(700 \mu \mathrm{L})$ was added, mixed by inversion, and incubated $10 \mathrm{~min}$ at room temperature. Mixtures were centrifuged at $16,000 \times \mathrm{g}$ for $5 \mathrm{~min}$ at $4{ }^{\circ} \mathrm{C}$. The aqueous phase was mixed with 1 volume of acid phenol:chloroform:isoamyl alcohol (25:24:1)and incubated for 5 $\min$ at room temperature. The mixture was centrifuged at $16,000 \times \mathrm{g}$ for $5 \mathrm{~min}$ at $4{ }^{\circ} \mathrm{C}$ and the aqueous phase was mixed with 1 volume chloroform, incubated $5 \mathrm{~min}$ at room temperature, and centrifuged at $16,000 \times \mathrm{g}$ for $5 \mathrm{~min}$ at $4{ }^{\circ} \mathrm{C}$. The resulting aqueous phase was mixed with 1 volume isopropanol and 0.1 volume sodium acetate $3 \mathrm{M}(\mathrm{pH}$ 5.2). The mixture was incubated overnight at $-20{ }^{\circ} \mathrm{C}$. RNA was precipitated through centrifugation at $16,000 \mathrm{x}$ for $30 \mathrm{~min}$ at 4 ${ }^{\circ} \mathrm{C}$ and washed twice with ethanol $70 \%(\mathrm{v} / \mathrm{v})$. RNA samples were air dried, suspended in nuclease free water, and treated with TURBO DNAse (AM1907) following manufacturer's instructions. Absence of genomic DNA was controlled by PCR of the the cadA gene with the same primers used for qPCR (Table S1) Reverse transcription reactions were carried out using 500 ng of RNA with the ImProm II Reverse Transcription system (Promega A3800) with random primers, following manufacturer's instructions.

\subsection{Quantitative polymerase chain reaction of $c D N A$}

Quantitative PCR was carried out with the Fast SYBRGreen Master Mix (Applied Biosystems, 4385612) in a qPCR Step One machine (Applied Biosystems, 271003314). Primers (Table S1) were used at $0.5 \mu \mathrm{M}$ each. PCR conditions included a hot start step at 95 ${ }^{\circ} \mathrm{C}$ for $20 \mathrm{~s}$, followed by 40 cycles of two steps amplification $\left(95^{\circ} \mathrm{C}\right.$ for $3 \mathrm{~s}, 60{ }^{\circ} \mathrm{C}$ for 30 $\mathrm{s})$. For each condition, three independent experiments each with at least two technical replicates 
were conducted. Bacteria incubated in absence of cadmium was used as the control condition. $\mathrm{Ct}$ values were normalized to expression of housekeeping $r p o Z$ and gyrB genes as described [41]. Fold changes were assessed by one sample $t$ test. Fold changes outside of $[+1,-1]$ range (Pvalues below 0.05) were significant.

\subsection{Construction of recombinant C. metallidurans and P. aeruginosa strains}

Cloning procedures were performed with E. coli DH5 $\alpha$ and SL17.1 $\lambda$ pir strains, high fidelity DNA polymerase (Invitrogen 1253216), fast digest restriction enzymes (Thermo Scientific), and T4 DNA ligase (Promega M1801), according to standard protocols provided by the manufacturers. Primer sequences for cloning are shown in Table S1.

To characterize the function of the urf2.2 gene product, the urf2.2 gene (RMET_RS31035) was overexpressed in C. metallidurans and P. aeruginosa. Briefly, urf2.2 was amplified from CH34 genomic DNA using an EcoRI restriction site flanked forward primer and a HindIII site flanked reverse primer. This amplicon was subcloned into pGEM-T vector (Promega A1360) through T4 ligase, following manufacturer's instructions. The recombinant vector was introduced into E. coli strain $\mathrm{DH} 5 \alpha$ by electrotransformation. Transformed E. coli was cultured overnight in LB broth with ampicillin $100 \mu \mathrm{g} \mathrm{mL} \mathrm{m}^{-1}$ at $37^{\circ} \mathrm{C}$. The urf 2.2 insert was recovered by plasmid miniprep and EcoRI/HindIII double digestion, and was further ligated into the EcoRI/HindIII digested pJBTc19 vector and electrotransformed into E. coli SL17.1 $\lambda$ pir donor strain. The donor strain E. coli SL17.1 $\lambda$ pir pJBTc19:urf2.2 was grown in LB broth with ampicillin $100 \mu \mathrm{g} \mathrm{mL} \mathrm{m}^{-1}$ and tetracycline $15 \mu \mathrm{g} \mathrm{mL}^{-1}$. C. metallidurans $\mathrm{CH} 34$ conjugation transfer was achieved by mixing cell suspensions of donor and recipient strains through vacuum filtration over a $0.2-\mu \mathrm{m}$ polycarbonate filter and incubated in nutrient agar (beef extract $1 \mathrm{~g} \mathrm{~L}^{-1}$, yeast extract $2 \mathrm{~g} \mathrm{~L}^{-1}$, peptone $5 \mathrm{~g} \mathrm{~L}^{-1}, \mathrm{NaCl} 5 \mathrm{~g} \mathrm{~L}^{-1}$ ) for 4 days at $30^{\circ} \mathrm{C}$. The biomass grown over the filter was spread on LPTMS agar supplemented with ampicillin $100 \mu \mathrm{g} \mathrm{mL} \mathrm{m}^{-1}$, tetracycline $15 \mu \mathrm{g} \mathrm{mL}-1$, and kanamycin $1 \mathrm{mg} \mathrm{mL}^{-1}$ to kill the donor E. coli strain. On the other hand, P. aeruginosa was transformed by electroporation and selection on LB agar supplemented with ampicillin $100 \mu \mathrm{g}$ $\mathrm{mL}^{-1}$, tetracycline $15 \mu \mathrm{g} \mathrm{mL} \mathrm{m}^{-1}$. All transformations were confirmed by double EcoRI/HindIII digestion of plasmid extraction products.

\section{Results}

\subsection{Cadmium exerts inhibition of biofilm formation through a decay in c-di-GMP levels}

Cell attachment assays show that cadmium exerts a dose dependent inhibition of early stages of biofilm formation in C. metallidurans CH34 (Figure 1A). Cell viability (as shown by $\mathrm{CFU} / \mathrm{mL}$ ) was not affected by the cadmium concentration range used, thus discarding a bias due to cell death (Figure 1A). At increasing cadmium concentrations, C. metallidurans macrocolonies on plates showed decreasing levels of EPS, which was observed by Congo Red staining (Figure 1B). A colorless extracellular matrix was observed at $8 \mathrm{mM}$ cadmium. To assess the role of the c-di-GMP pathway in these responses, nucleotide extracts were obtained from planktonic and biofilm cells after exposure to $2 \mathrm{mM}$ cadmium during $45 \mathrm{~min}$. Cadmium 
decreased c-di-GMP levels in cells of both lifestyles (Figure 1C). However, cadmium exerted a stronger c-di-GMP level decrease in planktonic cells, triggering an 8-fold drop of c-di-GMP concentration compared to control cells.

A
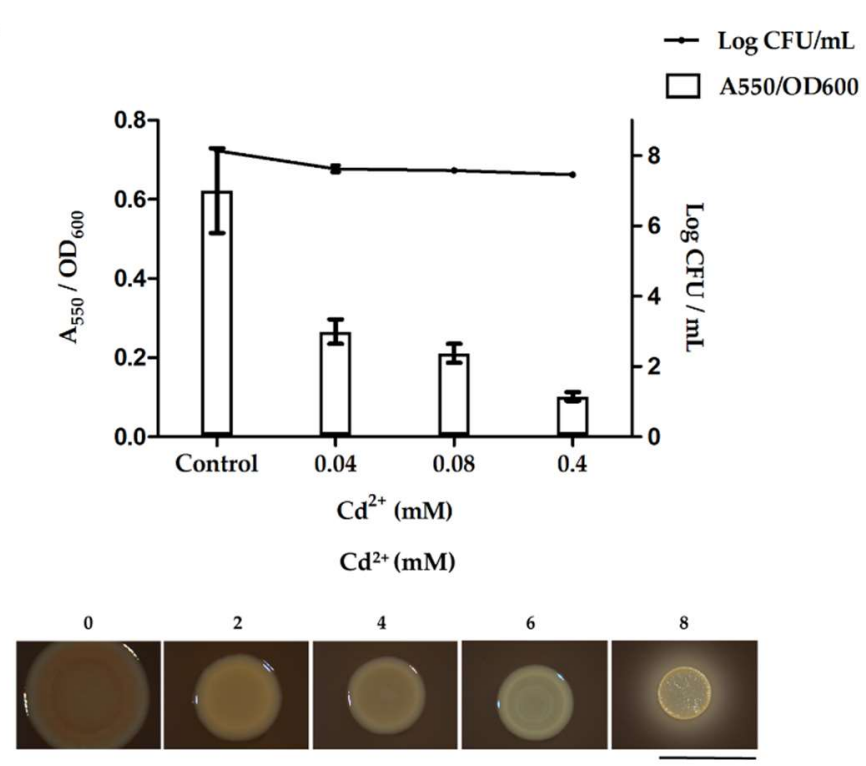

C

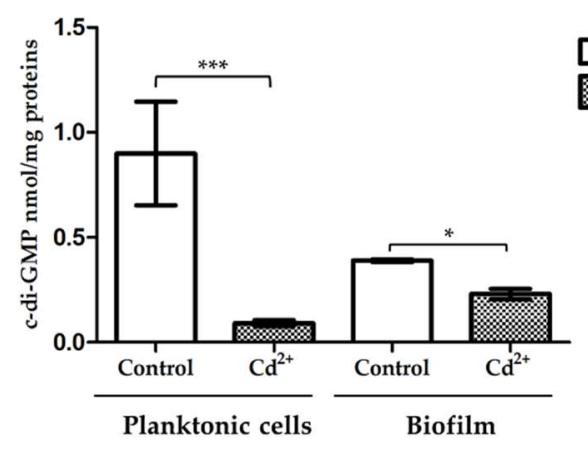

Figure 1. Effect of cadmium on $C$. metallidurans $\mathrm{CH} 34$ biofilm formation and c-di-GMP levels. A, Cell attachment and cell viability after $6 \mathrm{~h}$ of incubation in LPTMS broth at $30^{\circ} \mathrm{C}$. The means of three independent experiments and standard deviations are shown. B, Macrocolonies grown in Congo Red LB agar plates at different cadmium concentrations. Images were taken after five days of incubation at room temperature. The bar represents $1 \mathrm{~cm}$. C, c-di-GMP levels after $2 \mathrm{mM}$ cadmium exposure during $45 \mathrm{~min}$ in LPTMS broth (planktonic) or agar (biofilm). The c-di-GMP concentration was normalized respect to total protein content in each sample. The means of three independent experiments and standard deviations are shown. Significant differences assessed by $t$ test: $\left.P<0.05\left(^{*}\right), P<0.01\left(^{* *}\right), P<0.001{ }^{(* *}\right)$.

\subsection{Planktonic and biofilm cells have similar tolerance to cadmium}

The susceptibility to cadmium of $C$. metallidurans $\mathrm{CH} 34$ planktonic and biofilm cells was determined due to the cadmium effect favouring the planktonic lifestyle. For microtiter determinations of 
antimicrobial susceptibility, the Calgary Biofilm Device was used, which allows batch culture of biofilms on peg lids [39]. Microbicidal endpoints were determined quantitatively using viable cell counting following a MBEC assay (Figure S2) [21,53]. Planktonic and biofilm cells showed similar tolerance to cadmium (Figure 2).

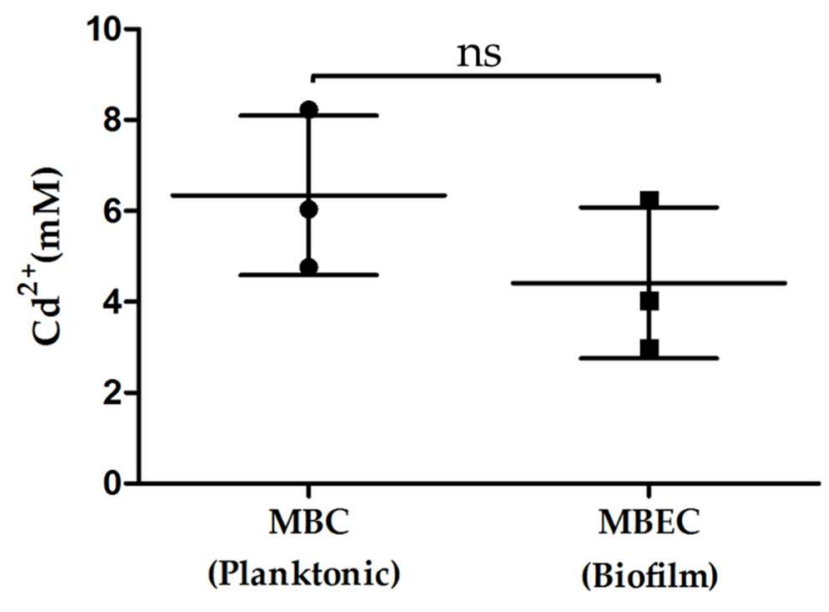

Figure 2. Cadmium susceptibility of $C$. metallidurans $\mathrm{CH} 34$ planktonic and biofilm cells. Values were determined by calculation in two independent kill curves experiments in triplicate. The mean of the cadmium concentration that kill $99.9 \%$ of cells is plotted. Dots and squares represent the interpolated values in the each kill curve. Significant differences assessed by $t$ test: ns, non-significant.

\subsection{C. metallidurans CH34 genome encodes functional DGCs and PDEs}

Genes encoding putative DGC and PDE domain-containing proteins in the C. metallidurans CH34 genome were searched due to the putative role of c-di-GMP in the cadmium response. To evaluate a role in the c-di-GMP metabolism, the functionality of proteins with GGDEF, EAL and HD-GYP domains encoded in the genome of $\mathrm{C}$. metallidurans $\mathrm{CH} 34$ were predicted through the analysis of the conservation of amino acid determinants for the catalytic activity (Figures S3, S4 and S5) [15-17]. C. metallidurans CH34 genome encodes 18 different GGDEF domain proteins, 10 EAL domain proteins, 12 GGDEF/EAL hybrid proteins, and 2 HD-GYP domain proteins. Since the functionality of all these $\mathrm{CH} 34$ proteins was unknown, the function of each protein was predicted based on conservation of at least $50 \%$ of the activesite motifs defined by crystallography [15-17] (Tables S2, S3 and S4). In our study, proteins with conservation of at least $50 \%$ amino acid determinants for the catalytic activity were predicted to be active proteins, whereas proteins with conservation of less than $50 \%$ amino acid determinants for the catalytic activity were predicted to be non-active. Seventeen of 18 annotated GGDEF domain proteins were predicted to possess DGC enzymatic activity. On the other hand, 9 of 10 annotated EAL domain proteins were predicted to have PDE enzymatic activity, whereas the RMET_RS19345 gene product was predicted to be non-active.

Among the 12 hybrid proteins, the GGDEF domain of RMET_RS19120 gene product was predicted to be non-active. In addition, both GGDEF and EAL domains of RMET_RS24490 and RMET_RS29670 gene products were also predicted to be non-active. The RMET_RS29670 gene product showed partial 
conservation in primary inhibition site motif, indicating c-di-GMP binding capabilities (Figure S5, Table S4). The EAL domain of two hybrid proteins (RMET_RS24490 and RMET_RS29670) was predicted to be non-active (Table S4). Finally, the 2 loci encoding HD-GYP domain PDEs (RMET_RS09120 and RMET_RS20080) were predicted to be non-active and were thus not further analyzed (Figure S5).

In summary, thirty six genes coding for proteins with catalytic active domains in the c-di-GMP metabolism were found in the $\mathrm{C}$. metallidurans $\mathrm{CH} 34$ genome. For these genes, accessory domains and orthology analyses were performed to select a subset of genes for further studies (Table S5).

An accessory domain analysis was performed with the proteins predicted to have catalytic active c-di-GMP domains (Figure 3). The cytoplasmic HAMP domain, important for receptor signal(s) transduction [42], and the extracellular CACHE sensor domains [43] were encoded exclusively in DGCs. The ionic strength sensitive domain CBS [44] was located exclusively in three hybrid proteins, including an uncommon localization between EAL and GGDEF domains in RMET_RS24295 gene product. An uncharacterized domain DUF3030 was observed in carboxy terminals of the EAL domain of the RMET_RS30310 and RMET_RS31035 genes proteins (Figure 3).

Five and four accessory domains were identified in single proteins, three of them in hybrid proteins. In DGC proteins, a Tsr_Tar chemoreceptor domain [45] was observed in the RMET_RS08460 gene product, a nucleotide binding GAF domain [46] in the RMET_RS19900 gene product and a histidine kinase domain HisK in the RMET_RS28515 gene product. The oxidative stress sensitive domain CSS identified in the EAL domain RMET_RS05485 and RMET_RS26980 genes products [47]. On the other hand, an integral membrane domain associated to gaseous ligand sensing (MHYT) [48] was identified in the hybrid protein RMET_RS22980, and a membrane-anchoring domain MASE1 [49] in the hybrid protein RMET_RSO2985.

Other accessory domains were transversally distributed between different proteins of c-di-GMP metabolism. For example, the phosphorylation receiver domains (REC) were identified in DGC RMET_RS20545 and in PDE RMET_RS20720 gene products. The gaseous ligand binding domain PAS [50] was observed in five DGCs (RMET_RS04365, RMET_RS08460,RMET_RS11180,RMET_RS28515 and RMET_RS29325) and three hybrid proteins (RMET_RS02985, RMET_RS11280 and RMET_RS28625) (Figure 3).

A gene orthology analysis in E. coli and P. aeruginosa genomes was performed. Based in sequence similarity and architectural domain profiles, nine CH34 orthologous DGC genes were identified in E. coli and P. aeruginosa (Table S5). Three DGCs (RMET_RS09375, RMET_RS11270 and RMET_RS19900) showed high identity with YedQ (27\%) [51], TpbB (55\%) [52] and YeaP (41\%) [53], respectively. All aforementioned gene products are enzymes that promote EPS production and surface adherence. The analyses of the PDEs revealed that, the CH34 RMET_RS05485 and RMET_RS26980 gene products possess high identity (33-34\%) to the PDE YjcC that is involved in the oxidative stress response and motility in $K$. pneumoniae [47], whereas the RMET_RS20720 gene product showed high identity (30\%) to RocR, which is involved in biofilm formation and virulence gene expression in P. aeruginosa [30]. Finally, the hybrid RMET_RS22980 gene product showed high identity (65\%) to the bifunctional enzyme MucR, which is involved in biofilm dispersion in P. aeruginosa [54]. 
The genomic context of c-di-GMP pathway genes and genes related to heavy metal resistance, motility and biofilm formation was analyzed. Five c-di-GMP pathway genes were located in plasmids associated to heavy metal resistance. The RMET_RS30470 gene that encodes a bifunctional DGC/PDE was located in the genomic cop-sil-nre-ncc genes island, which codes for the heavy metal resistance machinery in pMOL30 [55]. In addition, the RMET_RS29670 gene that codes a predicted non-active protein is located in C. metallidurans $\mathrm{CH} 34$ plasmid pMOL30, but outside of the heavy metal resistance genomic island [55]. The PDE encoding RMET_RS30310 gene is located in the pMOL30 Tn4378 mer operon between the merE gene and a gene encoding a recombinase, overlapping their ORFs in ninety four bases (Figure S6). An identical context shows the PDE encoding RMET_RS31035 gene in the pMOL28 Tn4380 mer operon. Both EAL domain PDEs showed 95.1\% sequence identity. The RMET_RS30310 and RMET_RS31035 genes are annotated as urf2 (for $\underline{u}$ nkown related function) genes. 


\section{A. GGDEF proteins}
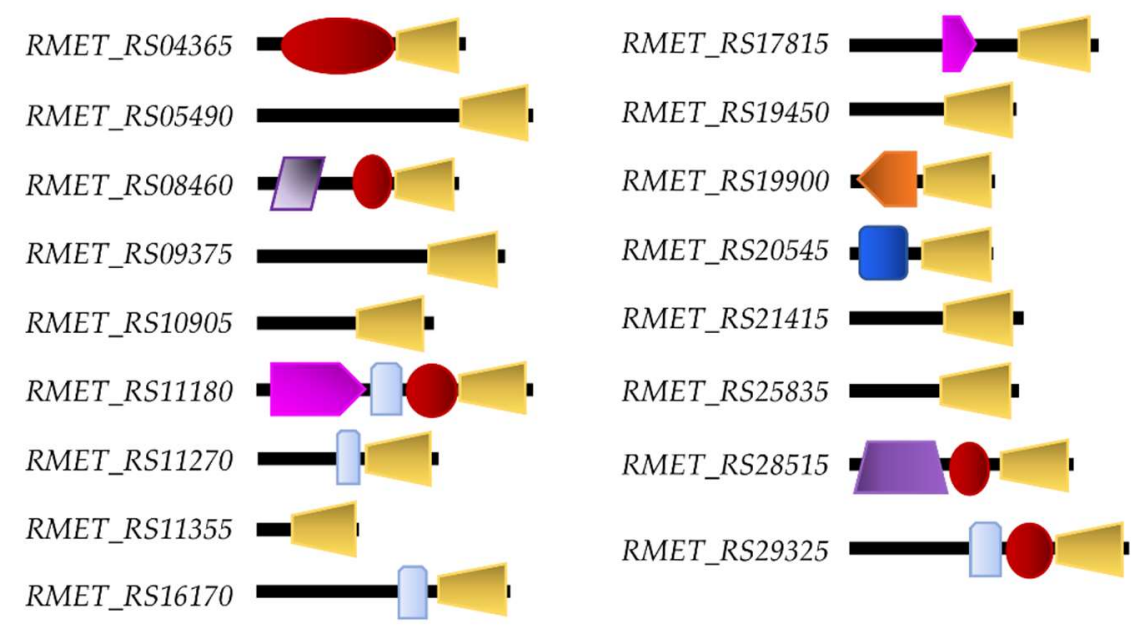

B. EAL proteins
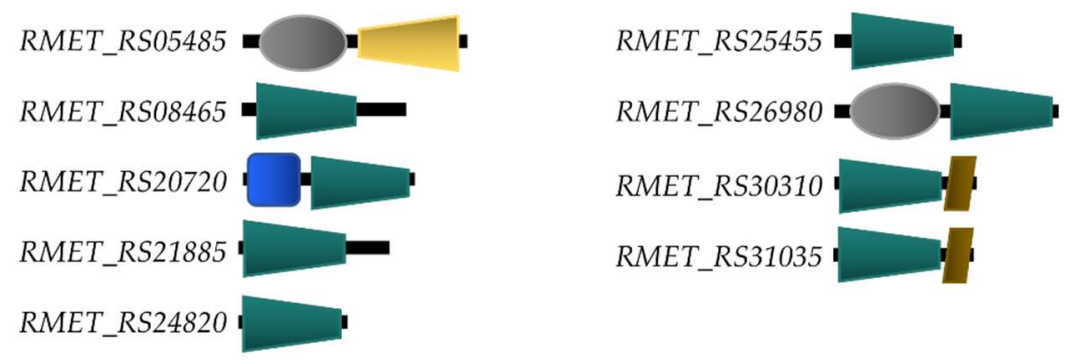

- $100 \mathrm{aa}$

C. Hybrid proteins
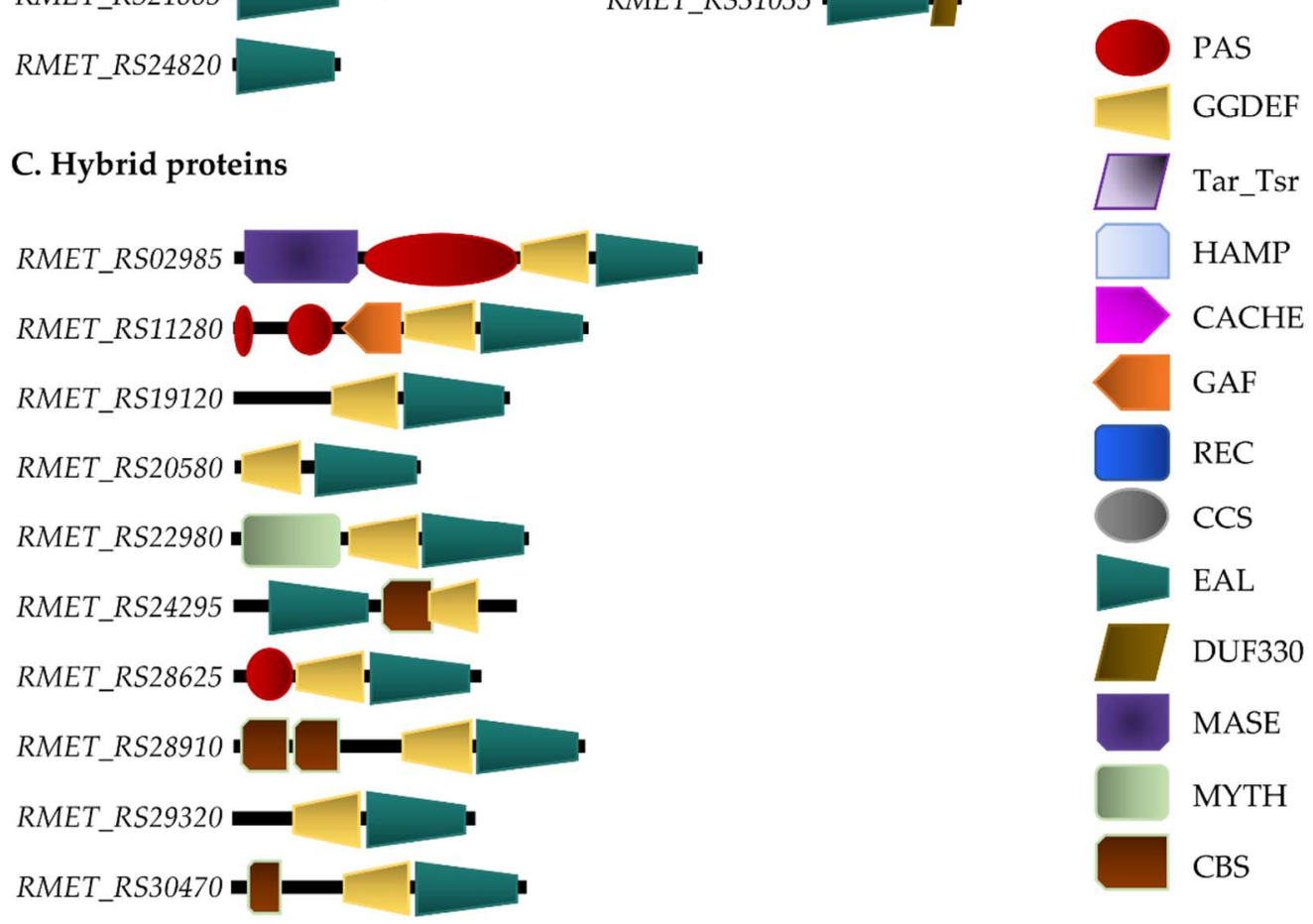

Figure 3. Domain-level depiction of c-di-GMP metabolism proteins from $C$. metallidurans $\mathrm{CH} 34$. Proteins with GGDEF/EAL domains that are catalytic active according to bioinformatic analyses are shown. 
Some c-di-GMP pathway genes identified are associated with biofilm formation. The RMET_RS11355 gene is located downstream to an operon gene organization that is associated with cellulose synthesis (Figure S6). The RMET_RS20545 gene is located downstream to a gene cluster associated to chemotaxis response, and the RMET_RS25455 gene is located upstream to a fimbrial synthesis gene cluster (Figure S6).

\subsection{C. metallidurans genome encodes protein effectors of c-di-GMP pathway}

C. metallidurans CH34 possesses four genes (RMET_RS05745, RMET_RS08705, RMET_RS09140 and $\left.R M E T \_R S 11325\right)$ encoding PilZ domain proteins. The PilZ domain protein encoded in RMET_RS09140 gene was discarded as c-di-GMP effector due to the absence of c-di-GMP binding motif (Figure S7). The hybrid GGDEF/EAL domains protein encoded by the RMET_RS29670 gene that was predicted to be catalytically non active, was included as potential effector of c-di-GMP pathway in C. metallidurans CH34 (Table S4). Local and pairwise sequence alignment determined the $\mathrm{CH} 34$ genes encoding orthologous proteins of the c-di-GMP effectors Bcam1349 (RMET_RS18290), which is the transcription factor that regulates biofilm formation in B. cenocepacia (Figure S8) and PelD (RMET_RS RS21490), which is a degenerate DGC that regulates Pel cationic exopolysaccharide synthesis in P. aeruginosa (Figure S9).

\subsection{Cadmium induce the expression of genes coding for PDE and heavy metal resistance genes}

A subset of 19 genes coding DGCs and PDEs were selected based on three criteria: i) genes coding for accessory domains associated to extracellular signals sensing, ii) genomic context associated to biofilm, motility or heavy metal resistance, and iii) orthology with E. coli or P. aeruginosa genes that encode enzymes of the c-di-GMP metabolism. Thus, the transcription levels of these genes (8 DGCs, 5 PDEs and 6 hybrids) were quantified after $45 \mathrm{~min}$ exposure to $2 \mathrm{mM}$ cadmium in both biofilm and planktonic cells (Figure 4A). In addition, 6 transcripts of c-di-GMP effectors were also quantified: three transcript encoding PilZ domain proteins that conserves the "c-di-GMP swicht" binding motif (RMET_RS05745, RMET_RS08705 and RMET_RS11325), one transcript encoding a degenerate hybrid GGDEF/EAL domain protein (RMET_RS29670), one transcript encoding for a PelD-like c-di-GMP effector (RMET_RS21490) and one transcript (RMET_RS18290) that encodes a protein with high identity (53\%) to Bcam1349, which is a c-di-GMP-dependent transcription factor in Burkholderia cenocepacia [34] (Figure 4B).

In both lifestyles, most of the selected transcripts (DGCs, PDEs and hybrids) showed a non-significant abundance fold change in response to cadmium (Figure 4A). In planktonic cells two exceptions were observed. The RMET_RS11180 gene that encodes a DGC that possesses HAMP and CACHE extracellular signal sensing domains was strongly downregulated ( $\sim$ fold $)$. The urf2 genes expression was upregulated ( $\sim 3$ fold). Primers amplified the two urf2 genes transcripts, hence this value is the sum of urf2.1 and urf2.2 transcripts.

After biofilm cells exposure to cadmium, a higher number of transcripts showed a significant fold change. The urf2 gene transcription increased very strongly ( 36 fold) in biofilms (Figure $4 \mathrm{~A})$. The transcription of two hybrids proteins were significantly downregulated by cadmium: RMET_RS02985 ( $\sim 6$ fold $)$ that encodes to an integral membrane protein with a MASE1 domain, and RMET_RS28910 ( 4 
fold) that encodes to a protein with two CBS domains. The RMET_RS11180 gene transcription was also significantly downregulated ( $\sim 3$ fold), which was also observed in planktonic cells.

Almost all effector transcripts assessed were significantly downregulated after cadmium exposure, in higher magnitude in biofilm cells (Figure 4B). Only the RMET_RS08705 and RMET_RS29670 transcripts were non-significantly regulated in planktonic conditions.

In addition, the transcription of two heavy metal resistance genes was analyzed. The transcription of the cadA gene that encodes a $\mathrm{Cd}^{2+} /$ ATPase protein transporter involved in cadmium resistance was monitored. As expected, after exposure to cadmium the cadA gene was strongly upregulated in both lifestyles at similar levels ( 10 fold) (Figure $4 \mathrm{C}$ ). The effect of cadmium on the expression of the mer $A$ genes that encodes a mercuric reductase and belongs to the mer operons $\operatorname{Tn} 4378$ and $\operatorname{Tn} 4380$, which also harbor the urf2 genes, was also analyzed. The primers used amplify both merA transcripts. Interestingly, cadmium induced the transcription of the merA genes in both lifestyles (Figure 4C), suggesting an induction of mercury resistance by cadmium. The upregulation by cadmium of the mer $A$ genes was much stronger in biofilms (121 fold) than in planktonic cells (14 fold).

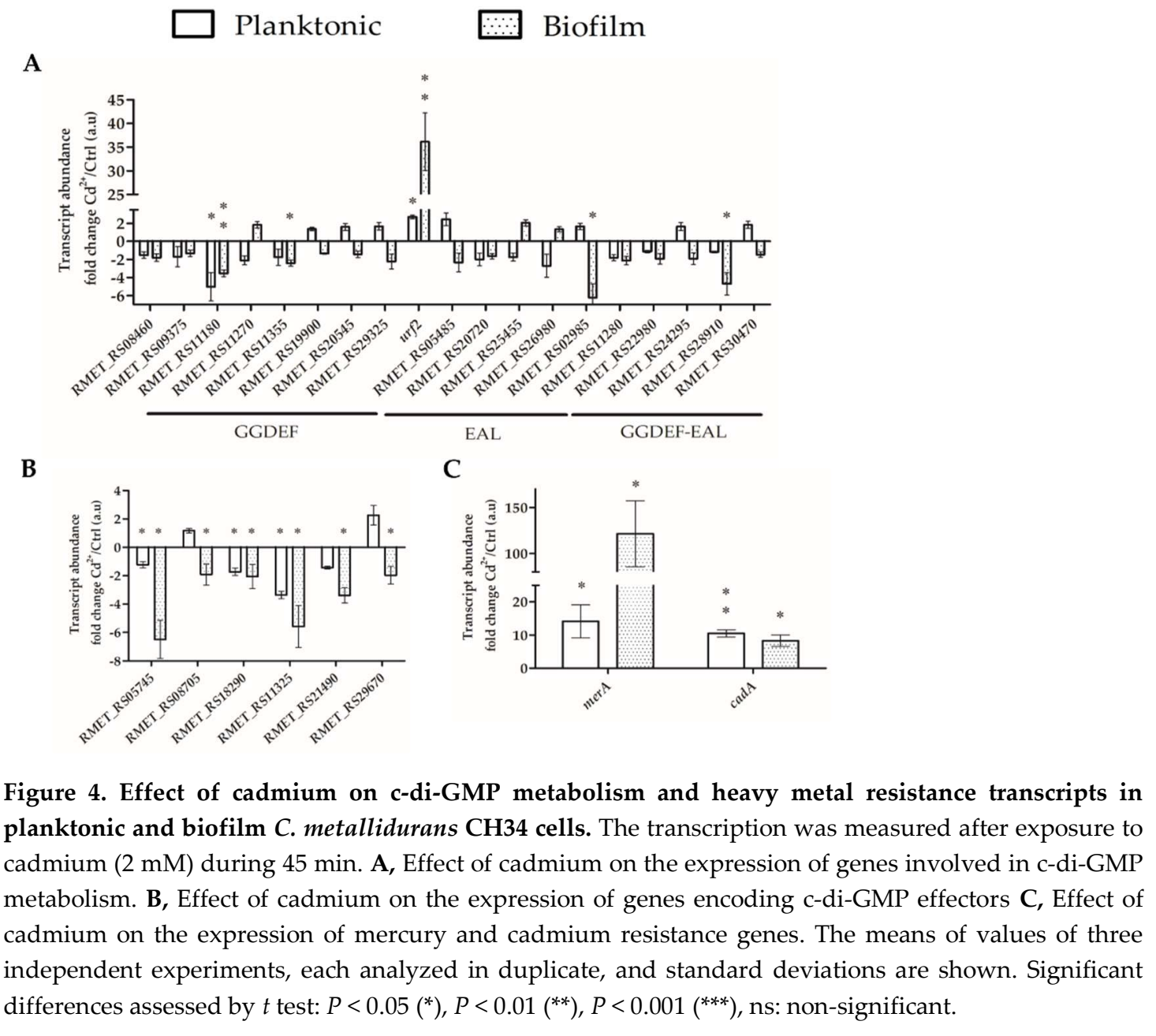




\subsection{The urf2 gene encodes a functional PDE}

The urf 2 gene is a component of the Tn501 mer operon. Although Tn501 and its derivatives were described decades ago [59], the Urf2 function remains unknown. Here, we are able for the first time to suggest a function. A complementation assay was developed in the PDE null mutant strain $P$. aeruginosa PAO1 $\triangle$ rocR to evaluate the effects of the protein encoded by the urf2 gene in biofilm formation and cdi-GMP levels. The complementation by the urf2.2 gene restored biofilm formation (Figure 5A) and c-diGMP levels (Figure 5B) at levels comparable to the wild-type PAO1 strain, indicating that urf2.2 gene encodes a functional PDE. Based on this data we propose to rename this specific gene as mrp2 gene for metal regulated phosphodiesterase and its copy on plasmid pMOL28 as mrp1 gene.

A

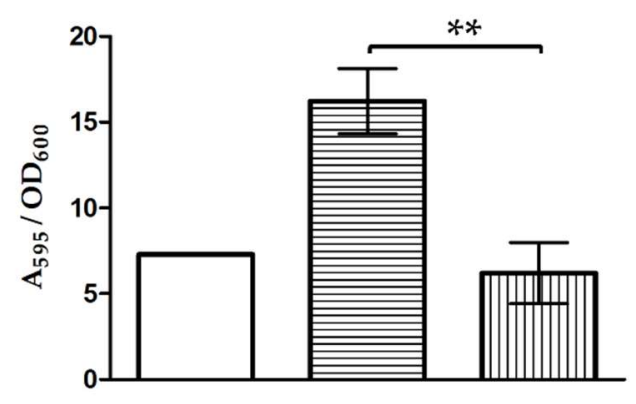

B

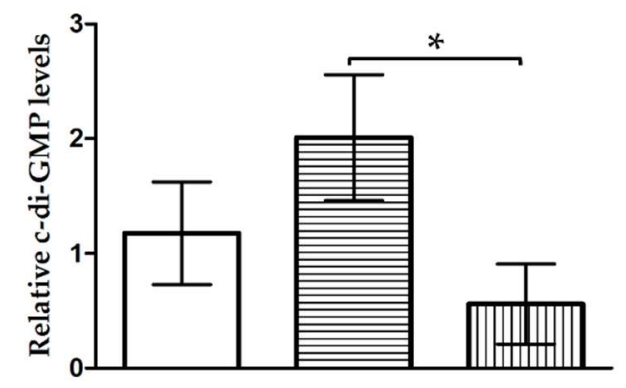

Figure 5. Complementation effects in P. aeruginosa PAO1 $\Delta$ rocR with pJBTc19:urf2.2. A, Biofilm formation at $6 \mathrm{~h}$ of incubation in 96 well plates. B: The c-di-GMP content in planktonic cells at $6 \mathrm{~h}$ of incubation in Erlenmeyer flasks. The means of three independent experiments and standard deviations are shown. Significant differences assessed by $t$ test: $P<0.05\left(^{*}\right), P<0.01\left(^{* *}\right)$.

\subsection{Effects of c-di-GMP metabolism disturbances in response to cadmium}

The relevance of c-di-GMP decrease for biofilm formation and cadmium response in C. metallidurans $\mathrm{CH} 34$ was assessed through the overexpression of the urf2.2 gene and the heterologous expression of the constitutive active DGC PleD* [26]. The overexpression of the urf2.2 gene has no significant effects on biofilm formation (Figure 6A) and EPS content in macrocolonies (Figure 6B). However, after overexpression of the urf2.2 gene a slight decrease in c-di-GMP levels in control planktonic cells were observed, which disappear after the exposure to cadmium (Figure 6C). Conversely, the heterologous expression of the PleD* DGC increased biofilm formation (Figure 6A), EPS content (Figure 6B) and c-diGMP levels in control cells and in cells incubated with cadmium (Figure 6C). 
To further assess the effects of these alterations in c-di-GMP metabolism in cadmium susceptibility, MBC and MBEC were determined in C. metallidurans transformed strains. The overexpression of the urf2.2 gene has no effect on cadmium susceptibility. Interestingly, the heterologous expression of PleD* DGC resulted in significant detrimental effects in cadmium tolerance (Figures 7 and S10) in both bacterial lifestyles.

A

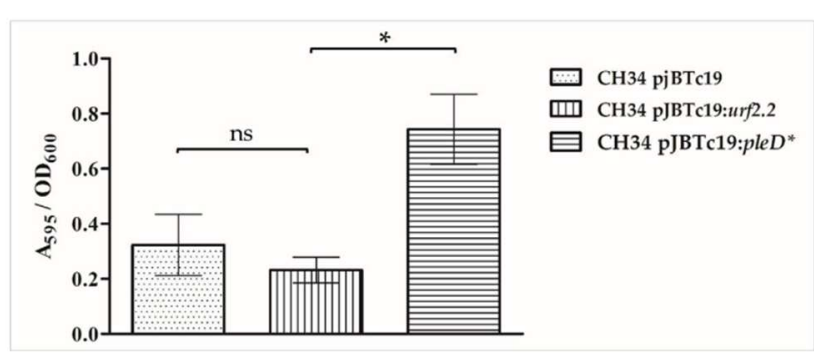

B

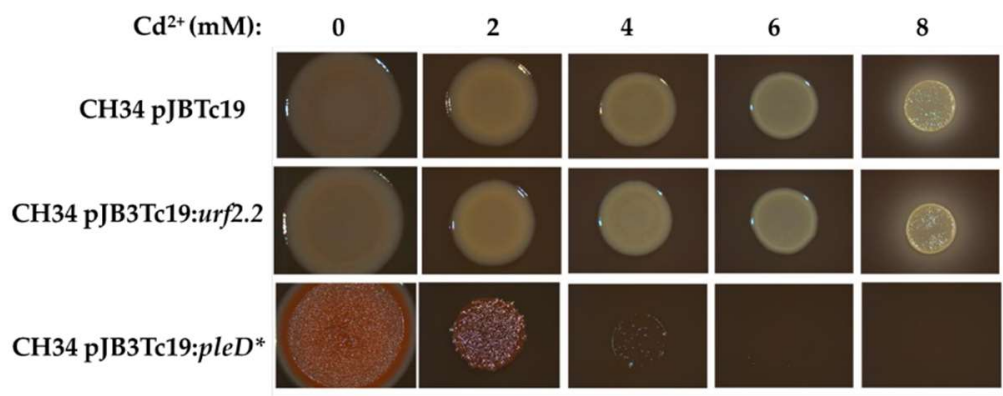

C

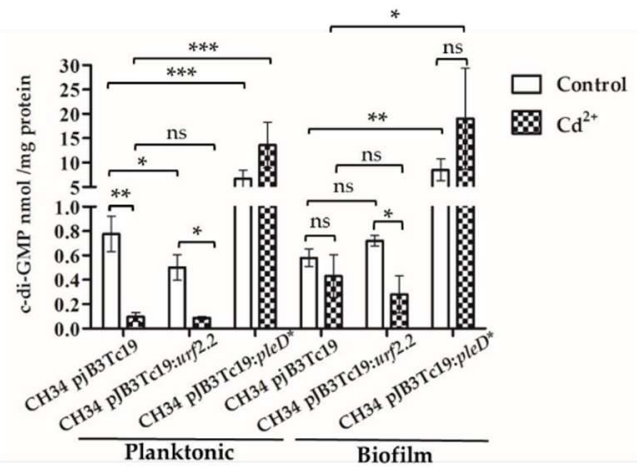

Figure 6. Effect of urf2.2 overexpression and ple $D^{*}$ heterologous expression on $C$. metallidurans $\mathrm{CH} 34$ biofilm formation and c-di-GMP metabolism. A: Biofilm formation. The means of three independent experiments and standard deviations are shown. Significant differences assessed by $t$ test: $P<0.05\left(^{*}\right)$, ns: not significant. B: Macrocolonies morphotype in presence of cadmium. C: Response in c-di-GMP levels after cadmium exposure. The means of three independent experiments and standard deviations are shown. Significant differences assessed by $t$ test: $P<0.05\left(^{*}\right), P<0.01\left({ }^{* *}\right), P<0.001\left({ }^{* * *}\right)$, ns: non-significant. 


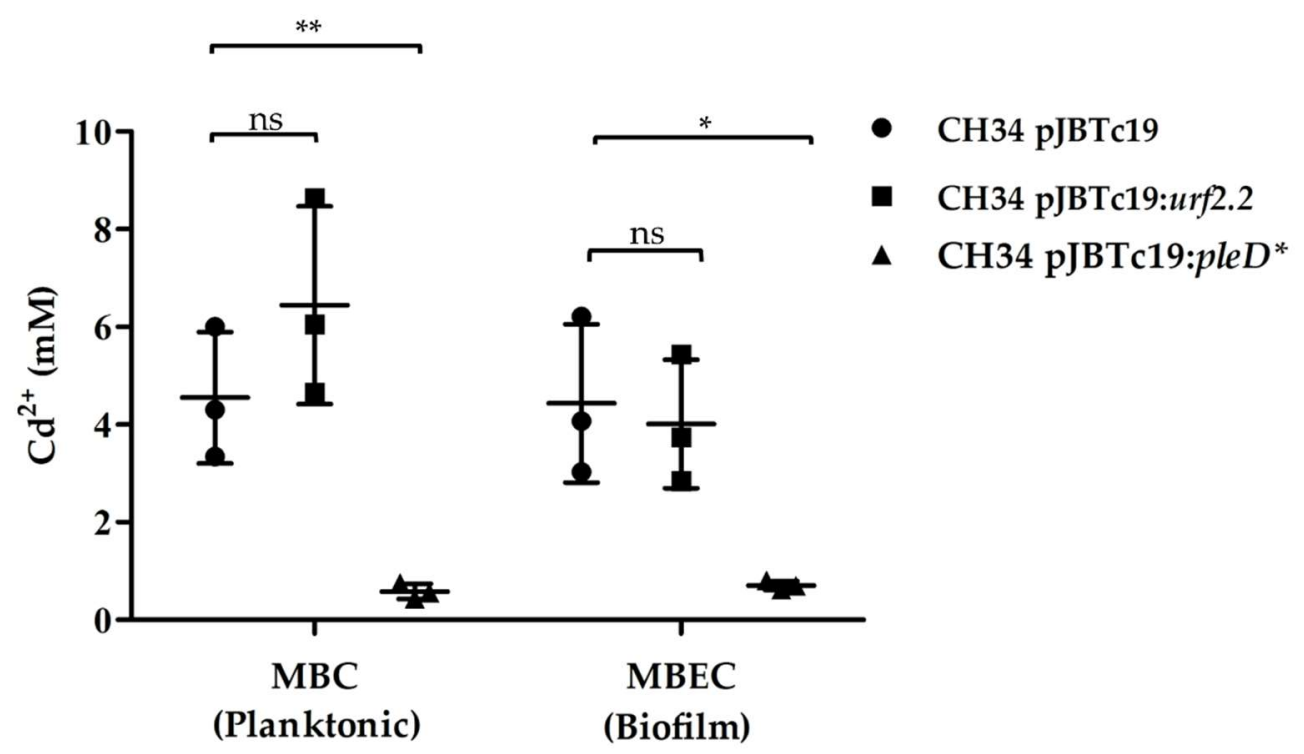

Figure 7. Effect of urf2.2 overexpression and pleD* heterologous expression on C. metallidurans $\mathrm{CH} 34$ tolerance to cadmium. The means of three independent experiments and standard deviations are shown. Significant differences assessed by $t$ test: $P<0.05\left({ }^{*}\right), P<0.01\left({ }^{*}\right)$, ns: non-significant.

\section{Discussion}

This study shows that cadmium inhibits biofilm formation in the model heavy metal-resistant strain C. metallidurans $\mathrm{CH} 34$, which correlates with a drop in the c-di-GMP levels. The upregulation of the PDE encoded by the urf2 genes is probably involved in the drop in c-di-GMP concentration. We propose to rename it as $\operatorname{mrp}$ (metal regulated $\underline{\mathrm{PDE}}$ ) gene based on this study and the location of its two copies (RMET_RS30310/mrp1 and RMET_RS31035/mrp2) in the two mer operons from the C. metallidurans pMOL28 and pMOL30 plasmids. The mer operons are part of transposons belonging to the Tn501/Tn21 family, the most widespread transposons families in terrestrial and marine environments [56,57]. Similar results on biofilms were reported by Agulló et al. (2017) describing that the toxic aromatic compound $p$ cymene reduced biofilm formation in the model aromatic-degrader B. xenovorans LB400. The reduced biofilm formation in LB400 cells grown on $p$-cymene correlated with a decrease of the DGC protein levels that probably reduced c-di-GMP levels [58].

In our study, of the 42 putative proteins involved in c-di-GMP metabolism coded in C. metallidurans $\mathrm{CH} 34$ genome, thirty six proteins with at least $50 \%$ conservation of amino acid determinants for the catalytic activity were predicted as active, whereas six were predicted to be non-active. The domain organization revealed a high proportion of stand-alone GGDEF (9) and EAL (6) domains, contrasting with the $0.03 \%$ and $20 \%$ of representation of these kind of architectures in Pfam database [59]. Strain $\mathrm{CH} 34$ is especially well adapted to harsh niches in which heavy metals are present [6], therefore, the 
presence of unknown accessory domains in the c-di-GMP signaling pathway proteins should not been excluded.

Until this study, the role of the urf2 gene from the mercury resistance operon was unknown [59]. This urf2 gene was the first gene encoding a protein with an EAL domain to be reported in Tn501 [56] and $T n 21$ transposon families [57]. It has been previously described that urf2.1 and urf2.2 genes are upregulated by mercury, cadmium, lead and zinc $[55,60]$. These heavy metals belong to the group 12 in the periodic table, and clustered into the same transcriptomic profile, i.e. regulates the same set of genes, based on microarrays data [60]. Our study establishes for the first time the catalytic functionality of the urf2 ( $m r p$ ) gene product, due to its ability to functionally replace RocR in P. aeruginosa PAO1 $\triangle$ rock in complementation assays. RocR is a PDE response regulator in the RocS1S2AR (or SadARS) twocomponent signaling system in P. aeruginosa [61]. This system controls bacterial biofilm formation by regulating the transcription of the cup fimbrial gene cluster by a poorly understood mechanism [61]. Crystallography studies revealed that RocR is a constitutively inhibited tetrameric PDE, which is activated after phosphorylation, a modification that exposes the catalytic EAL domains [62]. This mechanism can explain the absence of effects, either by overexpression or by transposon interruption of the rocR gene in P. aeruginosa biofilm formation in static conditions [61]. In contrast, the results obtained in our study showed a drop in c-di-GMP levels and a decreased biofilm formation in P. aeruginosa PAO1 $\triangle r o c R$ complemented with the CH34 mrp2 (urf2.2) gene (Figure 5). This discrepancy may be explained by differences in experimental strategies. Cells from a static culture after $20 \mathrm{~h}$ incubation [61] are in a different physiological state compared to the adhered biomass after $6 \mathrm{~h}$ incubation under stirred conditions (this study). This condition generates shearing forces that promote biofilm compaction and viscosity loss in the EPS matrix [63], which result in a biofilm more resistant to hydrodynamic erosion [64]. Another important difference between both studies was the incubation time. After $6 \mathrm{~h}$ incubation cells are in an early and reversible biofilm formation stage, in which the RocR regulation of the adhesins $\mathrm{CupB} / \mathrm{C}$ is more relevant than in a mature stage after $20 \mathrm{~h}$ incubation [61]. Thus, under the conditions used in our study, the urf2.2 gene product could replace the RocR role in biofilm formation and c-di-GMP hydrolysis.

The absence of differences in cadmium susceptibilities (Figure 2) between both bacterial lifestyles and the significant decrease of c-di-GMP concentration in planktonic cells in response to cadmium (Figure 1C) suggest that the response exceeds planktonic lifestyle promotion. In this sense, some PDEs such as YjcC in K. pneumoniae [47], CdgR in Salmonella typhimurium [66] and YgfF in E. coli [67] play a role in oxidative stress survival. Since heavy metal toxicity may be related to oxidative stress, this decrease in c-di-GMP concentration could be expected. The heterologous expression of a constitutively active DGC $\left(\mathrm{PleD}^{*}\right.$ ) increased the c-di-GMP levels and cadmium susceptibility in C. metallidurans $\mathrm{CH} 34$ (Figures 6 and 7). As the extracellular matrix production is an energetically expensive process [68], a constitutive activation of this machinery could deplete ATP cellular pools, depriving the cell to achieve efficient cadmium detoxification. Furthermore, a displacement of RNA polymerase II cores by a permanently active transcription factors in those operons could not be excluded, due to the wide diversity of sigma factors and transcriptional regulators which expression is regulated during exposure of $C$. metallidurans cells to heavy metals [60]. By overexpression of the C. metallidurans $\mathrm{CH} 34$ mrp gene, the role of the mrp 
gene product in the c-di-GMP metabolism in response to cadmium was only observed in planktonic cells with a slight decrease in c-di-GMP that correlates with a tendency to decrease biofilm formation. It is possible that the overexpression of the mrp gene from the plasmid pJBTc19:urf2.2 was not high enough to observe higher changes due to the high expression of the mrp genes from plasmids pMOL30 and pMOL28.

The mrp gene product domain architecture shows a C-terminal accessory domain DUF3030 (Pfam 11809), which is only present in a nitro reductase protein family. I-TASSER 3D prediction platform [69] identified five $\alpha$-helix in this region beyond EAL domain towards the C-terminal region. Thus, the mrp gene product may be an exceptional case of domain organization in intracellular signaling proteins, combining cytoplasmic sensor domains in its N-terminal extreme with C-terminal output domains [70]. Although the unknown function of the DUF3030 domain, it may play a role in the c-di-GMP metabolism in C. metallidurans $\mathrm{CH} 34$. Therefore, it will be useful to generate a C. metallidurans $\mathrm{CH} 34$ double mrp null mutant $\Delta u r f 2.1 \Delta u r f 2.2$ strain to evaluate the contribution of these PDEs either for cadmium tolerance or for the c-di-GMP mediated response to cadmium. As other members of this family of proteins, the mrp2 gene product is encoded in mobile genetic elements, indicating their biological significance during horizontal gene transfer [59]. Finally, an unexpected result was the strong increase (121 fold) by cadmium of the merA gene expression in C. metallidurans biofilm cells. A lower induction (14 fold) by cadmium of the merA gene expression was observed in planktonic cells. Previously, we have observed the upregulation by cadmium of the expression of the merT and merP genes in C. metallidurans planktonic cells [71]. The mer operon is also induced by cadmium in Nitrosomonas europaea [72]. All these results suggest a role of the mer operon in the protection towards cadmium. The flexible nature of the regulator MerR allows the interaction with other heavy metals such as cadmium, zinc, gold and silver, according to in vitro transcription studies [73], but with lower affinity than for mercury [74]. In contrast to the strong induction by cadmium of the expression of the mer $A$ gene ( 121 fold) in biofilm cells, a lower induction by cadmium of the cadA gene ( 10 fold) was observed, indicating a differential behavior of both operons in the sessile biofilm lifestyle. Previously, differential mercury resistance mechanisms of Desulfovibrio desulfuricans planktonic cells and biofilms have been reported [75], which resembles the response to cadmium in strain $\mathrm{CH} 34$.

\section{Conclusions}

Cadmium inhibits biofilm formation in C. metallidurans CH34 through a decrease in c-di-GMP levels in both planktonic and biofilm modes of growth. The response to cadmium of C. metallidurans $\mathrm{CH} 34$, which was isolated from a heavy metal-polluted slurry, suggests that the inhibition by cadmium of the biofilm formation mediated by the decrease of c-di-GMP should be relevant for bacterial fitness under this condition, favoring the planktonic lifestyle. However, both lifestyles showed similar tolerance to cadmium, thus probably the adaptive advantage of planktonic cells is just to move towards less toxic environments. Transcription analysis suggests an active role of a previously unknown catalytic functional PDE encoded by the urf2 genes of Tn4378 (pMOL28) and Tn4380 (pMOL30) mer operons from C. metallidurans $\mathrm{CH} 34$. Since this is the first report on the function of the urf 2 gene, the gene was renamed as $m r p 2$, for "metal regulated $\underline{p}$ hosphodiesterase". In conclusion, this study indicates that the response to 
8 of 42

cadmium in C. metallidurans $\mathrm{CH} 34$ involves a decrease in c-di-GMP content that inhibits the biofilm lifestyle.

Supplementary Materials: Table S1: Primers used in this work. Bioinformatic predictions of catalytic functionality of putative c-di-GMP metabolism protein was displayed in Table S2 (DGCs), Table S3 (PDE) and Table S4 (Hybrids). Table S5: Orthology analysis of putative DGC/PDEs encoded in C. metallidurans $\mathrm{CH} 34$ with E. coli K12 and P. aeruginosa PAO1 genomes. Figure S1: Experimental model used to expose planktonic and biofilm cells to cadmium.

Figure S2: Cadmium kill curves of $\mathrm{C}$. metallidurans $\mathrm{CH} 34$ in planktonic and biofilm lifestyles. Figure S3: Multiple alignment of GGDEF domains encoded in C. metallidurans CH34 genome. Figure S4: Multiple alignment of EAL domains encoded in $\mathrm{C}$. metallidurans $\mathrm{CH} 34$ genome. Figure S5: Multiple alignment of HD-GYP domains encoded in C. metallidurans CH34 genome. Figure S6: Genomic context of genes involved in c-di-GMP metabolism in C. metallidurans CH34. Figure S7: Multiple alignment of PilZ domains encoded in $C$. metallidurans $\mathrm{CH} 34$ genome. Figure S8: Global alignment between amino acidic sequences encoded by bcam1349 (B. cenocepacia) and RMET_RS18290 (C. metallidurans CH34) genes. Figure S9: Global alignment between aminoacidic sequences of c-di-GMP effector PelD encoded in genomes of $P$. aeruginosa PAO1 and C. metallidurans CH34. Figure S10: Cadmium kill curves of transformed strains of $\mathrm{C}$. metallidurans $\mathrm{CH} 34$ in planktonic and biofilm lifestyles.

Acknowledgments: The authors thank Dr. Juan San Juan and Dr. Daniel Pérez Mendoza for the donations of pJBTc19 and pJBTc19:pleD* vectors. To Nathalie Gugala for support with Calgary Biofilm Device. PA acknowledges MECESUP PhD fellowship (UCH 1107)). This work was supported by FONDECYT 1160702 (NG) and 1151174 (MS) (http://www.fondecyt.cl), Programa de Investigación Asociativa (PIA) Anillo ACT172128 GAMBIO (MS) and USM (MS) (http://www.usm.cl) grants.

Author Contributions: P.A., M.S., N.G. and R.T. conceived and designed the experiments; P.A. performed the experiments; P.A., M.S., N.G., R.T., S.F. and L.R. analyzed the data; M.S., N.G. and R.T. contributed reagents/materials/analysis tools; P.A., M.S., N.G., R.T. and S.F. wrote the paper.

Conflicts of Interest: The authors declare no conflict of interest.

\section{References:}

1. Begg, S. L.; Eijkelkamp, B. A.; Luo, Z.; Couñago, R. M.; Morey, J. R.; Maher, M. J.; Ong, C. Y.; McEwan, A. G.; Kobe, B.; O’Mara, M. L.; Paton, J. C.; McDevitt, C. A. Dysregulation of transition metal ion homeostasis is the molecular basis for cadmium toxicity in Streptococcus pneumoniae. Nat. Commun. 2015, 6:6418, doi:10.1038/ncomms7418.

2. Vallee, B. L.; Ulmer, D. D. Biochemical effects of mercury, cadmium, and lead. Annu. Rev. Biochem. 1972, 41, 91-128, doi:10.1146/annurev.bi.41.070172.000515. 
3. Nies, D. H. Microbial heavy-metal resistance. Appl. Microbiol. Biotechnol. 1999, 51, 730-50, doi:10.1007/s002530051457.

4. World Health Organization Safety evaluation of certain food additivies and contaminants, Geneve 2011, cadmium (addendum).

5. Mosa, K. A.; Saadoun, I.; Kumar, K.; Helmy, M.; Dhankher, O. P. Potential biotechnological strategies for the cleanup of heavy metals and metalloids. Front. Plant Sci. 2016, 7, 1-14, doi:10.3389/fpls.2016.00303.

6. Rojas, L.A.; Yáñez, C.; González, M.; Lobos, S.; Smalla, K.; Seeger, M. Characterization of the metabolically heavy metal-resistant Cupriavidus metallidurans strain MSR33 generated for mercury remediation. PLoS ONE 2011, 6(3):e17555, doi: 10.1371/journal.pone.0017555.

7. Harrison, J. J.; Ceri, H.; Turner, R. J. Multimetal resistance and tolerance in microbial biofilms. Nat. Rev. Microbiol. 2007, 5, 928-938, doi:10.1038/nrmicro1774.

8. Harrison, J. J.; Ceri, H.; Stremick, C.; Turner, R. J. Differences in biofilm and planktonic cell mediated reduction of metalloid oxyanions. FEMS Microbiol. Lett. 2004, 235, 357-62, doi:10.1016/j.femsle.2004.05.005.

9. Chen, M.; Zhou, X.; Liu, X.; Zeng, R. J.; Zhang, F.; Ye, J.; Zhou, S. Facilitated extracellular electron transfer of Geobacter sulfurreducens biofilm with in situ formed gold nanoparticles. Biosens. Bioelectron. 2018, doi:10.1016/j.bios.2018.02.030.

10. Espinoza-Tofalos, A.; Daghio, M.; González, M.; Pappacchini, M.; Franzetti A.; Seeger, M. Toluene degradation by Cupriavidus metallidurans $\mathrm{CH} 34$ in nitrate-reducing conditions and in Bioelectrochemical Systems. FEMS Microbiol. Lett 2018, 16, doi:10.1093/femsle/fny119/4996784.

11. Gugala, N.; Lemire, J. A.; Turner, R. J. The efficacy of different anti-microbial metals at preventing the formation of, and eradicating bacterial biofilms of pathogenic indicator strains. $J$. Antibiot. (Tokyo). 2017, 70, 775-780, doi:10.1038/ja.2017.10.

12. Harrison, J. J.; Ceri, H.; Stremick, C. A; Turner, R. J. Biofilm susceptibility to metal toxicity. Environ. Microbiol. 2004, 6, 1220-7, doi:10.1111/j.1462-2920.2004.00656.x.

13. Harrison, J. J.; Ceri, H.; Roper, N. J.; Badry, E. a; Sproule, K. M.; Turner, R. J. Persister cells mediate tolerance to metal oxyanions in Escherichia coli. Microbiology 2005, 151, 3181-95, doi:10.1099/mic.0.27794-0.

14. Jenal, U.; Reinders, A.; Lori, C. Cyclic di-GMP: Second messenger extraordinaire. Nat. Rev. Microbiol. 2017, 15, 271-284, doi:10.1038/nrmicro.2016.190.

15. Wassmann, P.; Chan, C.; Paul, R.; Beck, A.; Heerklotz, H.; Jenal, U.; Schirmer, T. Structure of $\mathrm{BeF}^{-}$-modified response regulator PleD: implications for diguanylate cyclase activation, catalysis, and feedback inhibition. Structure 2007, 15, 915-27, doi:10.1016/j.str.2007.06.016.

16. Tchigvintsev, A.; Xu, X.; Singer, A.; Chang, C.; Brown, G.; Proudfoot, M.; Cui, H.; Flick, R.; Anderson, W. F.; Joachimiak, A.; Galperin, M. Y.; Savchenko, A.; Yakunin, A. F. Structural insight into the mechanism of c-di-GMP hydrolysis by EAL domain phosphodiesterases. J. Mol. Biol. 2010, 402, 524-538, doi:10.1016/j.jmb.2010.07.050.

17. Lovering, A. L.; Capeness, M. J.; Lambert, C.; Hobley, L.; Sockett, R. E. The structure of an unconventional HD-GYP protein from Bdellovibrio reveals the roles of conserved residues in this 
class of Cyclic-di-GMP phosphodiesterases. mBio 2011, 2, 1-8, doi:10.1128/mBio.00163-11.

18. Jain, R.; Sliusarenko, O.; Kazmierczak, B. I. Interaction of the cyclic-di-GMP binding protein FimX and the Type 4 pilus assembly ATPase promotes pilus assembly. PLoS Pathog. 2017, 13, 123, doi:10.1371/journal.ppat.1006594.

19. Duerig, A.; Sören, A.; Folcher, M.; Nicollier, M.; Schwede, T.; Amiot, N.; Giese, B.; Jenal, U. Second messenger-mediated spatiotemporal control of protein degradation regulates bacterial cell cycle progression. Gene Dev. 2009, 23, 93-104, doi:10.1101/gad.502409.tion.

20. Habazettl, J.; Allan, M. G.; Jenal, U.; Grzesiek, S. Solution structure of the PilZ domain protein PA4608 complex with cyclic di-GMP identifies charge clustering as molecular readout. J. Biol. Chem. 2011, 286, 14304-14314, doi:10.1074/jbc.M110.209007.

21. Römling, U.; Galperin, M. Y.; Gomelsky, M. Cyclic di-GMP: the first 25 years of a universal bacterial second messenger. Microbiol. Mol. Biol. Rev. 2013, 77, 1-52, doi:10.1128/MMBR.00043-12.

22. Mergeay, M.; Nies, D.; Schlegel, H. G.; Gerits, J.; Charles, P.; Van Gijsegem, F. Alcaligenes eutrophus $\mathrm{CH} 34$ is a facultative chemolithotroph with plasmid-bound resistance to heavy metals. J. Bacteriol. 1985, 162, 328-34.

23. Collard, J. M.; Corbisier, P.; Diels, L.; Dong, Q.; Jeanthon, C.; Mergeay, M.; Taghavi, S.; van der Leie, D.; Wilmotte, A.; Wuertz, S. Plasmids for heavy metal resistance in Alcaligenes eutrophus CH34: Mechanisms and applications. FEMS Microbiol. Rev. 1994, 14, 405-414, doi:10.1111/j.15746976.1994.tb00115.x.

24. Janssen, P. J.; van Houdt, R.; Moors, H.; Monsieurs, P.; Morin, N.; Michaux, A.; Benotmane, M. A.; Leys, N.; Vallaeys, T.; Lapidus, A.; Monchy, S.; Médigue, C.; Taghavi, S.; McCorkle, S.; Dunn, J.; van der Lelie, D.; Mergeay, M. The complete genome sequence of Cupriavidus metallidurans strain $\mathrm{CH} 34$, a master survivalist in harsh and anthropogenic environments. PLoS One 2010, 5, doi:10.1371/journal.pone.0010433.

25. Nies, D. H. The biological chemistry of the transition metal "transportome" of Cupriavidus metallidurans. Metallomics 2016, 8, 481-507, doi:10.1039/C5MT00320B.

26. Maes, S.; Props, R.; Fitts, J. P.; De Smet, R.; Vanhaecke, F.; Boon, N.; Hennebel, T. Biological recovery of platinum complexes from diluted aqueous streams by axenic cultures. PLoS One 2017, 12, 1-17, doi:10.1371/journal.pone.0169093.

27. Montero-Silva, F.; Durán, N.; Seeger, M. Synthesis of extracellular gold nanoparticles using Cupriavidus metallidurans CH34 cells. IET Nanobiotechnology 2018, 12, 40-46, doi:10.1049/ietnbt.2017.0185.

28. Pérez-Mendoza, D.; Aragón, I. M.; Prada-Ramírez, H. A.; Romero-Jiménez, L.; Ramos, C.; Gallegos, M. -T.; Sanjuán, J. Responses to elevated c-di-GMP levels in mutualistic and pathogenic plant-interacting bacteria. PLoS One 2014, 9, doi:10.1371/journal.pone.0091645.

29. O'Toole, G.A.; Kolter, R. Initiation of biofilm formation in Pseudomonas fluorescens WCS365 proceeds via multiple, convergent signalling pathways: a genetic analysis. Mol. Microbiol. 1998, 28, 449-61.

30. Rao, F.; Yang, Y.; Qi, Y.; Liang, Z.-X. Catalytic mechanism of cyclic di-GMP-specific phosphodiesterase: A study of the EAL domain-containing RocR from Pseudomonas aeruginosa. J. 
Bacteriol. 2008, 190, 3622-3631, doi:10.1128/JB.00165-08.

31. Romero, D.; Aguilar, C.; Losick, R.; Kolter, R. Amyloid fibers provide structural integrity to Bacillus subtilis biofilms. Proc. Natl. Acad. Sci. 2010, 107, 2230-2234, doi:10.1073/pnas.0910560107.

32. Harrison, J. J.; Stremick, C. A; Turner, R. J.; Allan, N. D.; Olson, M. E.; Ceri, H. Microtiter susceptibility testing of microbes growing on peg lids: a miniaturized biofilm model for highthroughput screening. Nat. Protoc. 2010, 5, 1236-54, doi:10.1038/nprot.2010.71.

33. Li, T. N., Chin, K. H., Liu, J. H., Wang, A. H. -J., Chou, S. H. XC1028 from Xanthomonas campestris adopts a PilZ domain-like structure without a c-di-GMP switch. Proteins 2009, 75, 2, 282-288, doi: 10.1002/prot.22330.

34. Fazli, M.; Almblad, H.; Rybtke, M. L.; Givskov, M.; Eberl, L.; Tolker-Nielsen, T. Regulation of biofilm formation in Pseudomonas and Burkholderia species. Environ. Microbiol. 2014, 16, 196181, doi: 10.1111/1462-2920.

35. Thompson, J. D.; Higgins, D. G.; Gibson, T. J. Clustal-W-Improving the sensitivity of progressive multiple sequence alignment through sequence weighting, position-specific gap penalties and weight matrix choice. Nucleic Acids Res. 1994, 22, 4673-4680.

36. Katoh, K.; Misawa, K.; Kuma, K.; Miyata, T. MAFFT: a novel method for rapid multiple sequence alignment based on fast Fourier transform. Nucleic Acids Res. 2002, 30, 3059-3066, doi:10.1093/nar/gkf436.

37. Altschul, S. F.; Madden, T. L.; Schäffer, A. A.; Zhang, J.; Zhang, Z.; Miller, W.; Lipman, D. J. Gapped BLAST and PSI-BLAST:a new generation of protein database search programs. Nucleic Acids Res. 1997, 25, 3389-3402, doi:10.1093/nar/25.17.3389.

38. Geer, L. Y.; Domrachev, M.; Lipman, D. J.; Bryant, S. H. CDART: protein homology by domain architecture. Genome Res. 2002, 12, 1619-1623, doi:10.1101/gr.278202.

39. Bernstein, J. A.; Khodursky, A. B.; Lin, P.-H.; Lin-Chao, S.; Cohen, S. N. Global analysis of mRNA decay and abundance in Escherichia coli at single-gene resolution using two-color fluorescent DNA microarrays. Proc. Natl. Acad. Sci. 2002, 99, 9697-9702, doi:10.1073/pnas.112318199.

40. Sung, K.; Khan, S. A.; Nawaz, M. S.; Khan, A. A. A simple and efficient Triton X-100 boiling and chloroform extraction method of RNA isolation from Gram-positive and Gram-negative bacteria. FEMS Microbiol. Lett. 2003, 229, 97-101, doi:10.1016/S0378-1097(03)00791-2.

41. Hellemans, J.; Mortier, G.; De Paepe, A.; Speleman, F.; Vandesompele, J. qBase relative quantification framework and software for management and automated analysis of real-time quantitative PCR data. Genome Biol. 2007, 8, R19, doi:10.1186/gb-2007-8-2-r19.

42. Matamouros, S.; Hager, K. R.; Miller, S. I. HAMP domain rotation and tilting movements associated with signal transduction in the PhoQ sensor kinase. mBio 2015, 6(3):e00016-15 doi:10.1128/mBio.00616-15.

43. Upadhyay, A. A.; Fleetwood, A. D.; Adebali, O.; Finn, R. D.; Zhulin, I. B. Cache domains that are homologous to, but different from PAS domains comprise the largest superfamily of extracellular sensors in prokaryotes. PLoS Comput. Biol. 2016, 12(4):e1004862, doi:10.1371/journal.pcbi.1004862. 
44. Biemans-Oldehinkel, E.; Mahmood, N. A. B. N.; Poolman, B. A sensor for intracellular ionic strength. Proc. Natl. Acad. Sci. U. S. A. 2006, 103, 10624-10629, doi:10.1073/pnas.0603871103.

45. Tajima, H., Imada, K., Sakuma, M., Hattori, F., Nara, T., Kamo, N., Homma, M., Kawagishi, I. Ligand specificity determined by differentially arranged common ligand-binding residues in bacterial amino acid chemoreceptors Tsr and Tar. J. Biol. Chem. 2011, 49, 42200-42210, 10.1074/jbc.M111.221887.

46. Heikaus, C. C., Pandit, J., Klevit, R. E. Cyclic nucleotide binding GAF domains from phosphodiesterases: structural and mechanistic insights. Structure. 2009, 17 , 1551-1557, doi:10.1016/j.str.2009.07.019.

47. Huang, C.-J.; Wang, Z.-C.; Huang, H.-Y.; Huang H.-D.; Peng, H.-L. YjcC, a c-di-GMP phosphodiesterase protein, regulates the oxidative stress response and virulence of Klebsiella pneumoniae CG43. PLoS One 2013, 8, e66740, doi:10.1371/journal.pone.0066740.

48. Galperin, M. Y., Gaidenko, T. A., Mulkidjanian, A. Y., Nakano, M., Price, C. W. MHYT, a new integral membrane sensor domain. FEMS Microbiol. Lett. 2005, 205, 17-23, 10.1016/S03781097(01)00424-4.

49. Nikolskaya, A. N., Mulkidjanian, A. Y., Beech, I. B., Galperin, M. Y. MASE1 and MASE2: Two novel integral membrane sensory domains. J. Mol. Microbiol. Biotech. 2003, 5, 11-16, $10.1159 / 000068720$.

50. Henry, J. T.; Crosson, S. Ligand-binding PAS domains in a genomic, cellular, and structural context. Annu. Rev. Microbiol. 2011, 65, 261-86, doi:10.1146/annurev-micro-121809-151631.

51. Sanchez-Torres, V., Hu, H., Wood, T. K. GGDEF proteins YeaI, YedQ, and YfiN reduce early biofilm formation and swimming motility in Escherichia coli. 2011, 2, 651-658, 10.1007/s00253-0103074-5

52. Xu, K., Li, S. Y., Wen, L., Kan, B.A, Yuwei, Xu, Y., Jin, J., Wang, Y., Bartlam, M. Structural and biochemical analysis of tyrosine phosphatase related to biofilm formation A (TpbA) from the opportunistic pathogen Pseudomonas aeruginosa PAO1. PLoS One. 2015, 10, 1-16, 10.1371/journal.pone.0124330

53. Ryjenkov, D. A., Tarutina, M., Moskvin, O. V., Gomelsky, M. Cyclic diguanylate is a ubiquitous signaling molecule in bacteria: Insights into biochemistry of the GGDEF protein domain. J Bacteriol. 2005, 5, 1792-1798, 10.1128/JB.187.5.1792-1798.2005

54. Li, Y.; Heine, S.; Entian, M.; Sauer, K.; Frankenberg-Dinkel, N. NO-induced biofilm dispersion in Pseudomonas aeruginosa is mediated by an MHYT domain-coupled phosphodiesterase. J. Bacteriol. 2013, 195, 3531-3542, doi:10.1128/JB.01156-12.

55. Monsieurs, P.; Moors, H.; Van Houdt, R.; Janssen, P. J.; Janssen, A.; Coninx, I.; Mergeay, M.; Leys, N. Heavy metal resistance in Cupriavidus metallidurans $\mathrm{CH} 34$ is governed by an intricate transcriptional network. Biometals 2011, 24, 1133-51, doi:10.1007/s10534-011-9473-y.

56. Brown, N. L.; Misra, T. K.; Winnie, J. N.; Schmidt, A.; Seiff, M.; Silver, S. The nucleotide sequence of the mercuric resistance operons of plasmid R100 and transposon Tn501: further evidence for mer genes which enhance the activity of the mercuric ion detoxification system. MGG Mol. Gen. Genet. 1986, 202, 143-151, doi:10.1007/BF00330531. 
57. Liebert, C. A; Hall, R. M.; Summers, A. O. Transposon Tn21, flagship of the floating genome. Microbiol. Mol. Biol. Rev. 1999, 63, 507-522.

58. Agulló, L.; Romero-Silva, M.J.; Domenech, M.; Seeger, M. P-Cymene promotes its catabolism through the $\mathrm{p}$-Cymene and the $\mathrm{p}$-Cumate pathways, activates a stress response and reduces the biofilm formation in Burkholderia xenovorans LB400. PLoS One 2017, 12 (1):e00179-17, doi:10.1371/journal.pone.0169544.

59. Mouali, Y. E; Kim, H.; Ahmad, I.; Brauner, A.; Liu, Y.; Skurnik, M.; Galperin, M. Y.; Römling, U. Stand-alone EAL domain proteins form a distinct subclass of EAL proteins involved in regulation of cell motility and biofilm formation in enterobacteria. J. Bacteriol. 2017, 199, 1-17, doi:10.1128/JB.00179-17.

60. Monchy, S.; Benotmane, M. a; Janssen, P.; Vallaeys, T.; Taghavi, S.; van der Lelie, D.; Mergeay, M. Plasmids pMOL28 and pMOL30 of Cupriavidus metallidurans are specialized in the maximal viable response to heavy metals. J. Bacteriol. 2007, 189, 7417-25, doi:10.1128/JB.00375-07.

61. Kulasekara, H. D.; Ventre, I.; Kulasekara, B. R.; Lazdunski, A.; Filloux, A.; Lory, S. A novel twocomponent system controls the expression of Pseudomonas aeruginosa fimbrial cup genes. Mol. Microbiol. 2005, 55, 368-380, doi:10.1111/j.1365-2958.2004.04402.x.

62. Chen, M. W.; Kotaka, M.; Vonrhein, C.; Bricogne, G.; Rao, F.; Chuah, M. L. C.; Svergun, D.; Schneider, G.; Liang, Z.-X.; Lescar, J. Structural insights into the regulatory mechanism of the response regulator RocR from Pseudomonas aeruginosa in cyclic di-GMP signaling. J. Bacteriol. 2012, 194, 4837-46, doi:10.1128/JB.00560-12.

63. Goeres, D. M.; Loetterle, L. R.; Hamilton, M. A.; Murga, R.; Kirby, D. W.; Donlan, R. M. Statistical assessment of a laboratory method for growing biofilms. Microbiology 2005, 151, 757762, doi:10.1099/mic.0.27709-0.

64. Koechler, S.; Farasin, J.; Cleiss-Arnold, J.; Arsène-Ploetze, F. Toxic metal resistance in biofilms: diversity of microbial responses and their evolution. Res. Microbiol. 2015, doi:10.1016/j.resmic.2015.03.008.

65. Merritt, J. H., Brothers, K. M., Kuchma, S. L., O'Toole, G.A. SadC reciprocally influences biofilm formation and swarming motility via modulation of exopolysaccharide production and flagellar function. 2007, 189, 8154-8164, 10.1128/JB.00585-07.

66. Hisert, K. B.; MacCoss, M.; Shiloh, M. U.; Darwin, K. H.; Singh, S.; Jones, R.A; Ehrt, S.; Zhang, Z.; Gaffney, B. L.; Gandotra, S.; Holden, D. W.; Murray, D.; Nathan, C. A glutamate-alanine-leucine (EAL) domain protein of Salmonella controls bacterial survival in mice, antioxidant defence and killing of macrophages: role of cyclic diGMP. Mol. Microbiol. 2005, 56, 1234-45, doi:10.1111/j.1365-2958.2005.04632.x.

67. Lacey, M. M.; Partridge, J. D.; Green, J. Escherichia coli K-12 YfgF is an anaerobic cyclic di-GMP phosphodiesterase with roles in cell surface remodelling and the oxidative stress response. Microbiology 2010, 156, 2873-86, doi:10.1099/mic.0.037887-0.

68. Karunakaran, E., Mukherjee, J. Ramalingam, B., Biggs, C.A. "Biofilmology": a multidisciplinary review of the study of microbial biofilms. App. Microbiol. Biotech. 2011, 90, 1869-81, 10.1007/s00253-011-3293-4. 
69. Roy, A.; Kucukural, A.; Zhang, Y. I-TASSER: A unified platform for automated protein structure and function prediction. Nat. Protoc. 2010, 5, 725-738, doi:10.1038/nprot.2010.5.

70. Galperin, M. Y. Bacterial signal transduction network in a genomic perspective. Environ. Microbiol. 2004, 6, 552-567, doi:10.1111/j.1462-2920.2004.00633.x.

71. Rojas, L. Studies of bacterial bioremediation in soil microcosms contaminated with mercury (II) species, cadmium and copper, Universidad Técnica Federico Santa María, Valparaíso, Chile. 2011.

72. Park, S.; Ely, R. L. Candidate stress genes of Nitrosomonas europaea for monitoring inhibition of nitrification by heavy metals. Appl. Environ. Microbiol. 2008, 74, 5475-5482, doi:10.1128/AEM.00500-08.

73. Ralston, D. M.; O'Halloran, T. V. Ultrasensitivity and heavy-metal selectivity of the allosterically modulated MerR transcription complex. Proc. Natl. Acad. Sci. U. S. A. 1990, 87, 3846-3850, doi:10.1073/pnas.87.10.3846.

74. Wang, D.; Huang, S.; Liu, P.; Liu, X.; He, Y.; Chen, W.; Hu, Q.; Wei, T.; Gan, J.; Ma, J.; Chen, H. Structural Analysis of the Hg(II)-Regulatory Protein Tn501 MerR from Pseudomonas aeruginosa. Sci. Rep. 2016, 6, 1-9, doi:10.1038/srep33391.

75. Lin, T. Y.; Kampalath, R. A.; Lin, C. C.; Zhang, M.; Chavarria, K.; Lacson, J.; Jay, J. A. Investigation of mercury methylation pathways in biofilm versus planktonic cultures of Desulfovibrio desulfuricans. Environ. Sci. Technol. 2013, 47, 5695-5702, doi:10.1021/es400079 
Table S1. Primers used in this study

\begin{tabular}{|c|c|c|c|}
\hline ORF & Orientation & 5'-3' Sequence & Amplicon (pb) \\
\hline \multirow{2}{*}{$R M E T \_R S 02985$} & Fwd & AGCGCGGTTTCGGTGATTT & \multirow{2}{*}{127} \\
\hline & Rev & TGGTGTCGATCAACCTGTCT & \\
\hline \multirow{2}{*}{ RMET_RS05485 } & Fwd & GTGCATTGCTTGGATGGCTT & \multirow{2}{*}{145} \\
\hline & Rev & ACGCCTACGCATTCGTTGT & \\
\hline \multirow{2}{*}{$R M E T \_R S 05490$} & Fwd & GCTTGGGTTCGCAACTCCTT & \multirow{2}{*}{124} \\
\hline & Rev & ACATGCTGGTGCATTGTGCT & \\
\hline \multirow{2}{*}{$R M E T \_R S 08460$} & Fwd & GGAATCATATGCCCAACCGCTAAG & \multirow{2}{*}{120} \\
\hline & Rev & ACGTATCCGTCAAACCGCAACA & \\
\hline \multirow{2}{*}{$R M E T \_R S 08465$} & Fwd & GCCAAGAGTACCGATTGCGT & \multirow{2}{*}{133} \\
\hline & Rev & ATGTGGATGCGCTGCACTTT & \\
\hline \multirow{2}{*}{$R M E T \_R S 09375$} & Fwd & GGAAACAGCGGCCTGATCAT & \multirow{2}{*}{135} \\
\hline & Rev & AATTGCCAGCGTGAAGCAGA & \\
\hline \multirow{2}{*}{$R M E T \_R S 11180$} & Fwd & TGGCCATCGCCAATCATGTT & \multirow{2}{*}{125} \\
\hline & Rev & AGAAAGGCCCGTGATCTGGT & \\
\hline \multirow{2}{*}{$R M E T \_R S 11270$} & Fwd & CGCGTTTGGACAGCGAATG & \multirow{2}{*}{113} \\
\hline & Rev & CGTGCTGAAGCTGGTTTTGC & \\
\hline \multirow{2}{*}{$R M E T \_R S 11280$} & Fwd & TGCCGTCGCGTGGAAAGAAT & \multirow{2}{*}{121} \\
\hline & Rev & TGTCGAATGCGGCAAGCAGA & \\
\hline \multirow{2}{*}{$R M E T \_R S 11355$} & Fwd & CCATCGCCGGACATCGTTT & \multirow{2}{*}{139} \\
\hline & Rev & GCCTCGCTTGGCTTCATACA & \\
\hline \multirow{2}{*}{$R M E T \_R S 16170$} & Fwd & TCTGGCTGCATTCGCTGTTT & \multirow{2}{*}{133} \\
\hline & Rev & CGGATTTCGCCACGGTAGTT & \\
\hline \multirow{2}{*}{$R M E T \_R S 19900$} & Fwd & GCCGACGTCACGATCGATTA & \multirow{2}{*}{139} \\
\hline & Rev & CGTTTGGGCCAGATTGCTTG & \\
\hline \multirow{2}{*}{$R M E T \_R S 20545$} & Fwd & AAGCTTCCGGATTCGATCGAGTTG & \multirow{2}{*}{148} \\
\hline & Rev & TTAGCCGCTGCAGTTCGAGATT & \\
\hline RMET RS20720 & Fwd & GCTGGTCAGATCACGCAACT & 127 \\
\hline & Rev & TGGCCAAGCCGCTGAATTT & 127 \\
\hline$R M F T R S 22980$ & Fwd & GTCGATGGCGGTCAACCTTT & 115 \\
\hline & Rev & TCGAGCGTCAATCGTCTTGG & \\
\hline RMFT RS28910 & Fwd & GTGCATGGCCAGATGGTTCA & 149 \\
\hline К & Rev & CGAAAGAACGGCGAGCTGTA & \\
\hline RMET RS29325 & Fwd & ACGCCTTCGAAAGCCAGTT & 123 \\
\hline & Rev & TGGCATGGCCGTGTATGTC & \\
\hline RMET RS29670 & Fwd & TCCGCCAGGTTAAGCAAACA & 127 \\
\hline & Rev & AAGCGAATCGTGCCCTTTGT & \\
\hline RMFT $R S 30470$ & Fwd & TCGCGCCTTTATCCATGACA & 132 \\
\hline NVILA - KOSOT/ & Rev & ACCGACACTTGCCAAACGTA & 102 \\
\hline urf2 & Fwd & CACGCTCAAGATCGACCAAT & 133 \\
\hline & $\operatorname{Rev}$ & AAGACTCGCCGATGTTTCCA & \\
\hline rpoZ & Fwd & CGCGTATTACCGTCGAAGA & 123 \\
\hline
\end{tabular}




\begin{tabular}{lccc} 
& Rev & TGTCCTTTGCCTCGACCTT & \\
\hline \multirow{2}{*}{$g y r B$} & Fwd & AGAAAACGAGGTCGCCAAGA & 132 \\
& Rev & GAAACGAGCTTGTCCTTGGT & \\
\hline \multirow{2}{*}{$u r f 2.2$} & Fwd & AATAATAAGCTTATGAGCGCTTTCCGG & \multirow{2}{*}{1050} \\
& Rev & AATAATGAATTCATGCCGCCGCCGGCA & \\
\hline
\end{tabular}

Table S2. Prediction of the diguanylate cyclase functionality of GGDEF domain proteins encoded in $C$. metallidurans $\mathrm{CH} 34$ genome.

\begin{tabular}{|c|c|c|c|c|c|}
\hline \multicolumn{6}{|c|}{ GGDEF domain DGCs } \\
\hline Locus & Replicon & $\begin{array}{c}\text { Active site } \\
\quad(7 \text { aa) }\end{array}$ & $\begin{array}{l}\text { Ip }{ }^{a} \text { site } \\
\text { (3 aa) }\end{array}$ & 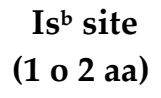 & Prediction \\
\hline$R M E T \_R S 04365$ & CHR1 & 6 & 0 & 0 & Active \\
\hline RMET_RS05490 & CHR1 & 7 & 3 & 0 & Active \\
\hline$R M E T \_R S 08460$ & CHR1 & 6 & 1 & 0 & Active \\
\hline$R M E T \_R S 09375$ & CHR1 & 7 & 3 & 2 & Active \\
\hline$R M E T \_R S 10905$ & CHR1 & 7 & 3 & 0 & Active \\
\hline$R M E T \_R S 11180$ & CHR1 & 6 & 2 & 0 & Active \\
\hline$R M E T \_R S 11270$ & CHR1 & 6 & 0 & 0 & Active \\
\hline$R M E T \_R S 11355$ & CHR1 & 7 & 0 & 0 & Active \\
\hline$R M E T \_R S 16170$ & CHR1 & 6 & 3 & 0 & Active \\
\hline$R M E T \_R S 17815$ & CHR1 & 7 & 1 & 2 & Active \\
\hline$R M E T \_R S 19450$ & CHR2 & 6 & 0 & 0 & Active \\
\hline$R M E T \_R S 19900$ & CHR2 & 6 & 1 & 2 & Active \\
\hline$R M E T \_R S 20545$ & CHR2 & 7 & 3 & 2 & Active \\
\hline$R M E T \_R S 21415$ & CHR2 & 7 & 3 & 0 & Active \\
\hline$R M E T \_R S 25835$ & CHR2 & 7 & 0 & 1 & Active \\
\hline$R M E T \_R S 28515$ & CHR2 & 7 & 0 & 0 & Active \\
\hline$R M E T \_R S 28900$ & CHR2 & 3 & 0 & 0 & Non Active \\
\hline RMET_RS29325 & CHR2 & 7 & 0 & 0 & Active \\
\hline
\end{tabular}


Table S3. Prediction of the phosphodiesterase functionality of EAL domain proteins encoded in $C$. metallidurans $\mathrm{CH} 34$ genome.

EAL domain PDEs

\begin{tabular}{|c|c|c|c|}
\hline Locus & Replicon & $\begin{array}{c}\text { Active site } \\
\text { (10 aa) }\end{array}$ & Prediction \\
\hline RMET_RS05485 & CHR1 & 10 & Active \\
\hline RMET_RS08465 & CHR1 & 9 & Active \\
\hline$R M E T \_R S 19345$ & CHR2 & 6 & Non active \\
\hline RMET_RS20720 & CHR2 & 10 & Active \\
\hline$R M E T \_R S 21885$ & CHR2 & 9 & Active \\
\hline$R M E T \_R S 24820$ & CHR2 & 10 & Active \\
\hline$R M E T \_R S 25455$ & CHR2 & 9 & Active \\
\hline RMET_RS26980 & CHR2 & 9 & Active \\
\hline$R M E T \_R S 30310$ & pMOL30 & 10 & Active \\
\hline RMET_RS31035 & pMOL28 & 10 & Active \\
\hline
\end{tabular}


Table S4. Bioinformatic prediction of the catalytic functionality of EAL \& GGDEF domain proteins encoded in $C$. metallidurans $\mathrm{CH} 34$ genome.

\begin{tabular}{|c|c|c|c|c|c|c|c|}
\hline \multicolumn{8}{|c|}{ Hybrid proteins } \\
\hline \multirow[b]{2}{*}{ Locus } & \multirow[b]{2}{*}{ Replicon } & \multicolumn{4}{|c|}{ GGDEF } & \multicolumn{2}{|c|}{ EAL } \\
\hline & & $\begin{array}{c}\text { Active site } \\
\text { (7 aa) }\end{array}$ & $\begin{array}{l}\text { Ip }{ }^{a} \text { site } \\
\text { (3 aa) }\end{array}$ & 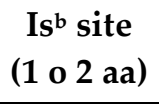 & Prediction & $\begin{array}{c}\text { Active site } \\
\text { (12 aa) }\end{array}$ & Prediction \\
\hline RMET_RS02985 & CHR1 & 7 & 2 & 0 & Active & 12 & Active \\
\hline$R M E T \_R S 11280$ & CHR2 & 4 & 2 & 0 & Active & 12 & Active \\
\hline$R M E T \_R S 19120$ & CHR2 & 3 & 1 & 0 & Non active & 12 & Active \\
\hline RMET_RS20580 & CHR2 & 5 & 0 & 0 & Active & 11 & Active \\
\hline$R M E T \_R S 24490$ & CHR2 & 2 & 0 & 0 & Non active & 6 & Non active \\
\hline$R M E T \_R S 22980$ & CHR2 & 7 & 0 & 0 & Active & 12 & Active \\
\hline$R M E T \_R S 24295$ & CHR2 & 7 & 0 & 0 & Active & 10 & Active \\
\hline$R M E T \_R S 28625$ & CHR2 & 7 & 1 & 0 & Active & 12 & Active \\
\hline$R M E T \_R S 28910$ & CHR2 & 6 & 1 & 2 & Active & 12 & Active \\
\hline$R M E T \_R S 29320$ & CHR2 & 6 & 0 & 0 & Active & 12 & Active \\
\hline$R M E T \_R S 29670$ & pMOL30 & 1 & 1 & 0 & Non active & 4 & Non active \\
\hline RMET_RS30470 & pMOL30 & 7 & 2 & 0 & Active & 12 & Active \\
\hline
\end{tabular}

a: Primary inhibition site, b: Secondary inhibition site 
Table S5. Orthology analysis of putative DGC/PDEs encoded in C. metallidurans CH34 and in E. coli K12 and P. aeruginosa PAO1 genomes. Parenthesis represents the length of each aminoacidic sequence. Genes in bold were selected for transcriptomic analysis.

\begin{tabular}{|c|c|c|c|c|c|c|}
\hline \multicolumn{2}{|c|}{ C. metallidurans $\mathrm{CH} 34$ gene products } & \multicolumn{5}{|c|}{ Related gene products } \\
\hline Locus & Domain architecture (aa) & Ref. Sequence & Organism & Function & $\%$ Id & Domain architecture (aa) \\
\hline \multicolumn{7}{|l|}{ GGDEF ORF } \\
\hline RMET_RS04365 & PAS-GGDEF(492) & MorA & P. aeruginosa PAO1 & DGC-PDE & 73 & BaeS-PAS-GGDEF-EAL (1415) \\
\hline RMET_RS05490 & GGDEF (653) & NP_251560.1 & P. aeruginosa $\mathrm{PAO} 1$ & Hyp & 33 & GGDEF (525) \\
\hline RMET_RS08460 & Tar_Tsr-PAS-GGDEF (546) & NP_249266.1 & P. aeruginosa PAO1 & Hyp & 44 & PBP-PAS-PAS-PAS-GGDEF-EAL (1245) \\
\hline$R M E T \_R S 09375$ & GGDEF (586) & YedQ & E. coli $\mathrm{K} 12$ & DGC & 27 & GGDEF (558) \\
\hline RMET_RS10905 & GGDEF (416) & AID76695.1 & P. aeruginosa $\mathrm{PAO} 1$ & Hyp & 43 & DNAPollII- SMCN-GGDEF (671) \\
\hline$R M E T \_R S 11180$ & CACHE-HAMP-PAS-GGDEF (654) & EHS35231.1 & P. aeruginosa PAO1 & Hyp & 30 & CHASE-HAMP-PAS-GGDEF (638) \\
\hline RMET_RS11270 & HAMP-GGDEF (426) & TpbB & P. aeruginosa PAO1 & DGC & 55 & HAMP-GGDEF (435) \\
\hline$R M E T \_R S 11355$ & GGDEF (237) & AID76049.1 & E. coli $\mathrm{K} 12$ & DGC & 42 & REC-REC-GGDEF (542) \\
\hline$R M E T \_R S 16170$ & HAMP-GGDEF (599) & NP_251560.1 & P. aeruginosa $\mathrm{PAO} 1$ & Hyp & 45 & GGDEF (525) \\
\hline RMET_RS17815 & CACHE-GGDEF (587) & YedQ & E. coli $\mathrm{K} 12$ & DGC & 27 & GGDEF (558) \\
\hline$R M E T \_R S 19450$ & GGDEF (392) & NP_250418.1 & P. aeruginosa PAO1 & Hyp & 37 & MHYT- GGDEF (685) \\
\hline RMET_RS19900 & GAF-GGDEF (338) & YeaP & E. coli $\mathrm{K} 12$ & DGC & 41 & GAF-GGDEF (341) \\
\hline$R M E T \_R S 20545$ & REC-GGDEF (335) & EHS43875.1 & P. aeruginosa PAO1 & Hyp & 72 & REC-GGDEF (347) \\
\hline RMET_RS21415 & GGDEF (409) & AID74892.1 & P. aeruginosa $\mathrm{PAO} 1$ & DGC & 44 & REC-GGDEF (347) \\
\hline$R M E T \_R S 25835$ & GGDEF (400) & WP_077873855.1 & E. coli $\mathrm{K} 12$ & Hyp & 35 & GGDEF (252) \\
\hline RMET_RS28515 & HisK-PAS-GGDEF (530) & NP_252391.1 & P. aeruginosa $\mathrm{PAO} 1$ & Hyp & 35 & REC-REC-GGDEF (347) \\
\hline RMET_RS29325 & HAMP-PAS-GGDEF (662) & NP_249266.1 & P. aeruginosa PAO1 & Hyp & 30 & PBP-PAS-PAS-PAS-GGDEF (1245) \\
\hline \multicolumn{7}{|l|}{ EAL ORF } \\
\hline RMET_RS05485 & CSS-EAL (530) & $\mathrm{YJcC}$ & E. coli $\mathrm{K} 12$ & PDE & 33 & CSS-EAL (516) \\
\hline$R M E T \_R S 08465$ & EAL (385) & MucR & P. aeruginosa PAO1 & PDE & 33 & MHYT-GGDEF-EAL (685) \\
\hline RMET_RS20720 & REC-EAL (404) & RocR & P. aeruginosa PAO1 & PDE & 30 & REC-EAL (392) \\
\hline
\end{tabular}


Continuing from Table S3Table S3.

\begin{tabular}{|c|c|c|c|c|c|c|}
\hline$R M E T \_R S 21885$ & EAL (353) & AID75563.1 & P. aeruginosa PAO1 & PDE & 33 & GGDEF-EAL (687) \\
\hline RMET_RS24820 & EAL (254) & AID74466.1 & P. aeruginosa PAO1 & Hyp & 42 & EAL-CBS-GGDEF (582) \\
\hline$R M E T \_R S 25455$ & EAL (298) & MorA & P. aeruginosa PAO1 & PDE & 36 & HisK-PAS-GGDEF- EAL (1415) \\
\hline RMET_RS26980 & CSS-EAL (529) & $\mathrm{YJcC}$ & E. coli $\mathrm{K} 12$ & PDE & 34 & CSS-EAL (516) \\
\hline RMET_RS30310 & EAL-DUF3030 (333) & MorA & P. aeruginosa PAO1 & PDE & 45 & HisK-PAS-GGDEF- EAL (1415) \\
\hline RMET_RS31035 & EAL-DUF3030 (329) & MorA & P. aeruginosa PAO1 & PDE & 45 & HisK-PAS-GGDEF- EAL (1415) \\
\hline \multicolumn{7}{|l|}{ Hybrid ORF } \\
\hline RMET_RS02985 & MASE1-PAS-GGDEF-EAL (1121) & NP_249872.1 & P. aeruginosa PAO1 & Hyp & 47 & PAS-PAS-GGDEF- EAL (1120) \\
\hline$R M E T \_R S 11280$ & PAS-PAS-GAF-GGDEF-EAL (850) & DosP & E. coli $\mathrm{K} 12$ & PDE & 32 & PAS-PAS-GGDEF - EAL (799) \\
\hline RMET_RS19120 & GGDEF-EAL (660) & AID74522.1 & P. aeruginosa PAO1 & Hyp & 33 & MHYT-GGDEF-EAL (726) \\
\hline RMET_RS20580 & GGDEF-EAL (441) & AID75563.1 & P. aeruginosa PAO1 & Hyp & 39 & GGDEF-EAL (687) \\
\hline$R M E T \_R S 22980$ & MHYT-GGDEF-EAL (709) & MucR & P. aeruginosa PAO1 & PDE & 65 & MHYT-GGDEF-EAL (685) \\
\hline$R M E T \_R S 24295$ & EAL-CBS-GGDEF (676) & WP_079279815.1 & P. aeruginosa PAO1 & Hyp & 34 & EAL-CBS-GGDEF (601) \\
\hline$R M E T \_R S 28625$ & PAS-GGDEF-EAL (589) & MucR & P. aeruginosa PAO1 & PDE & 42 & MHYT-GGDEF-EAL (685) \\
\hline RMET_RS28910 & CBS-CBS-GGDEF-EAL (839) & NP_249266.1 & P. aeruginosa PAO1 & PDE & 48 & PBP - PAS - GGDEF-EAL (1245) \\
\hline RMET_RS29320 & GGDEF-EAL (581) & AID74522.1 & P. aeruginosa PAO1 & Hyp & 41 & MHYT-GGDEF-EAL (726) \\
\hline RMET_RS30470 & CBS-GGDEF-EAL (705) & AID71820.1 & P. aeruginosa PAO1 & Нур & 40 & PBP-PAS-PAS-PAS-GGDEF-EAL (1245) \\
\hline
\end{tabular}




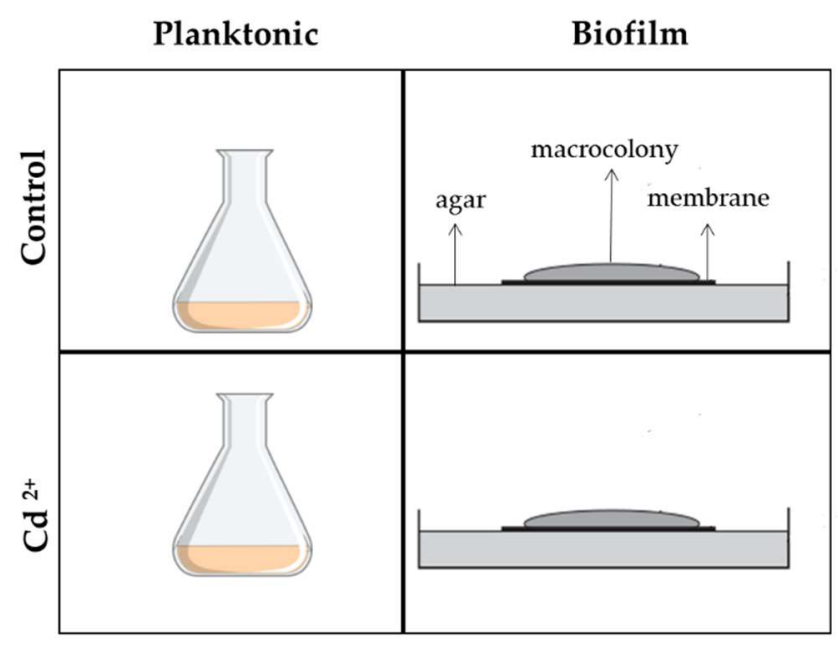

Figure S1. Experimental model used for the exposure to cadmium of planktonic and biofilm cells. Exposure of planktonic cells to cadmium ( $2 \mathrm{mM}$ ) during $45 \mathrm{~min}$. Exposure of biofilm cells to cadmium ( $2 \mathrm{mM}$ ) by transferring the macrocolony grown on polycarbonate membranes from a control to a $2 \mathrm{mM}$ cadmium-containing medium. 
2 of 42

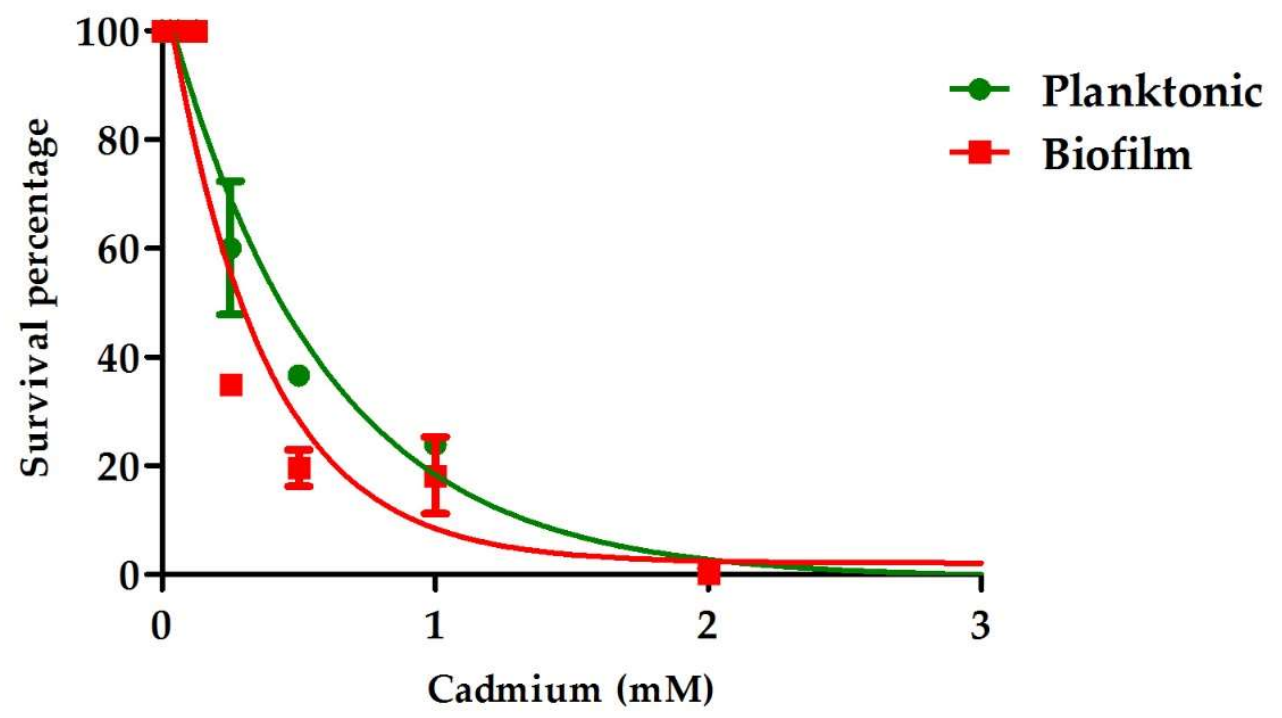

Figure S2: Cadmium kill curves of $C$. metallidurans $\mathrm{CH} 34$ in planktonic and biofilm lifestyles. Dots corresponds to relative viability means \pm standard deviation obtained from two biological replicates, each one by three technical replicates. Continuous lines represent non-linear regressions calculated for each strain to get susceptibility parameters (MBC \& MBEC) trough interpolation. 


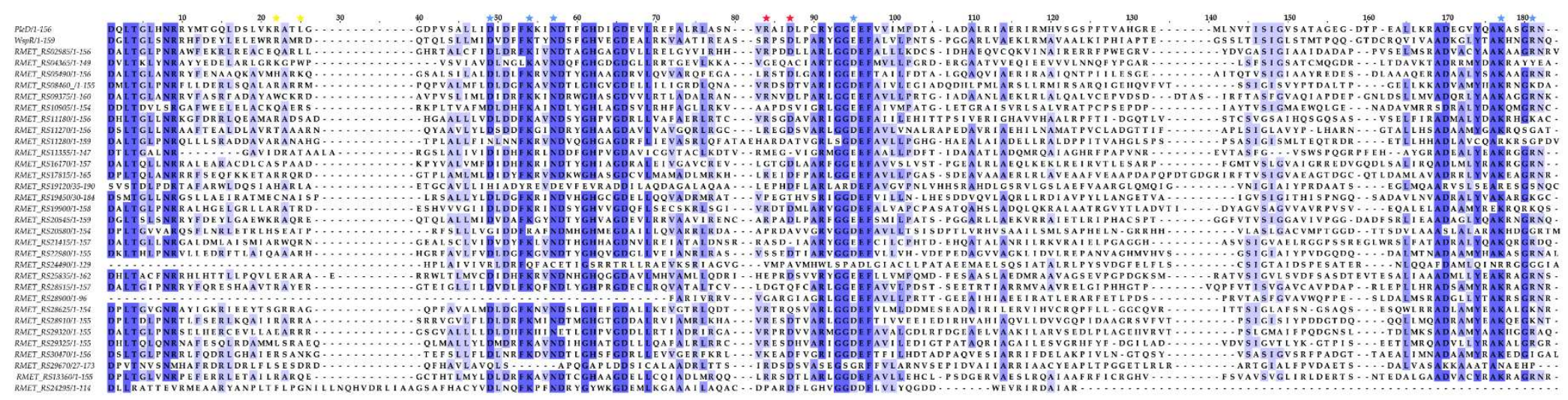

Figure S3. Multiple alignment of GGDEF domains encoded in C. metallidurans CH34 genome. As reference GGDEF domains of the functional DGCs PleD (Caulobacter crescentus) and WspR (P. aeruginosa). Symbols corresponds to determinant residues in catalytic activity. Blue: Active site, Red: Primary inhibition site, Yellow: Secondary inhibition site. Alignments performed trough ClustalW method. 


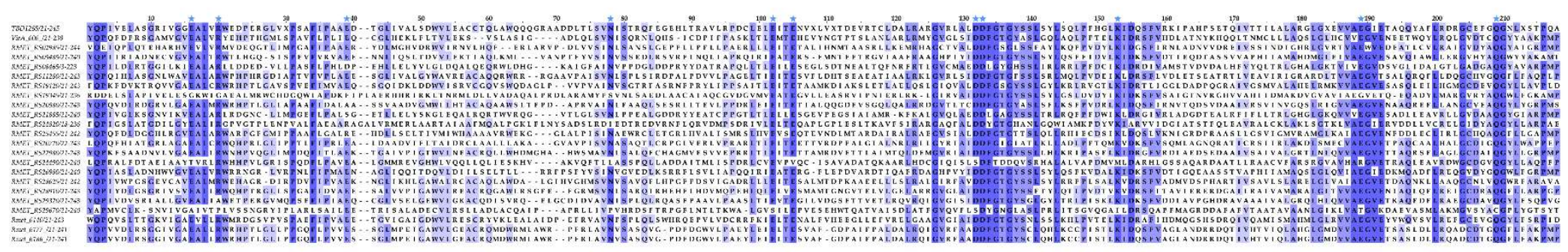

Figure S4. Multiple alignment of EAL domains encoded in C. metallidurans CH34 genome. As reference EAL domains of the functional PDEs TBD_1265 (Thiobacillus denitrificans) and VieA (Vibrio cholerae). Blue Symbols corresponds to determinant residues in catalytic activity. Alignments performed trough ClustalW method. 
TBD_1265/131-270

RMET_RS09120/30-344

RMET_RS09120/30-344
RMET_RS20080/590-943

TBD_1265/131-270

TBD_LT_RSO9120130-34

RMET_RS20080/590-943

TBD_1265/131-270

RMET_RS09120/30-344

TBD_1265/131-270

RMET_RS09120/30-344

RMET_RS20080/590-943

TBD_1265/131-270

RMET_RS09120/30-344

RMET_RS20080/590-943
131 AQALSAVMNIENT DKT I SHHGVTVSTLS IALAQKLGITDPKKT … . . . QLLTLGALLHDYGHH . . . . . . . . . HSPLNLNQP 197

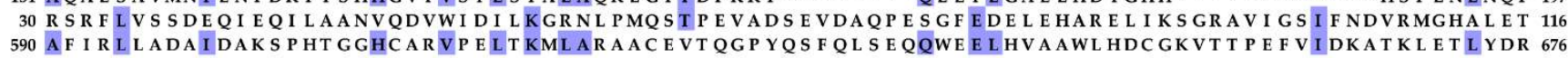

198 L DSMS P E DL AL WKK

WKKHPIEGAQKVQDKKHFDOTVIN.

Q

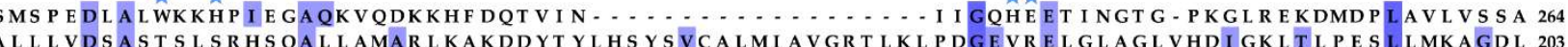
677 I HEVRMR FEVIKRDAEIOCLOS A A

$265 \stackrel{\star}{N A M D R} \stackrel{\star}{\star}$

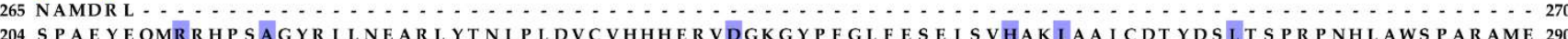
764 HEEFARKCR S PAHALPT OERLL ADR DDHR I ERGARDVMP PDNPWGFKRKVPRYLYDHGEIHNLTIGRGTLSEEERYKVEDHIVQTOI 850

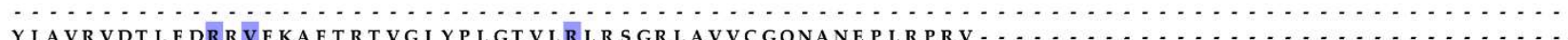

851 ML SRLPF PKHLRNVPE I AGGHHEKMDGT GYPRGLTR NQMS PLARMMAI ADI FEALTAADRPYKKAKTLSE S IGIMARLKAQQHIDGE 937

938 LFDLF

Figure S5. Multiple alignment of HD-GYP domains encoded in C. metallidurans CH34 genome. As reference HD-GYP domains of the functional PDE Bd1817 (Bdellovibrio bacteriovorus). Blue symbols corresponds to determinant residues in catalytic activity. Alignments performed trough ClustalW method. 


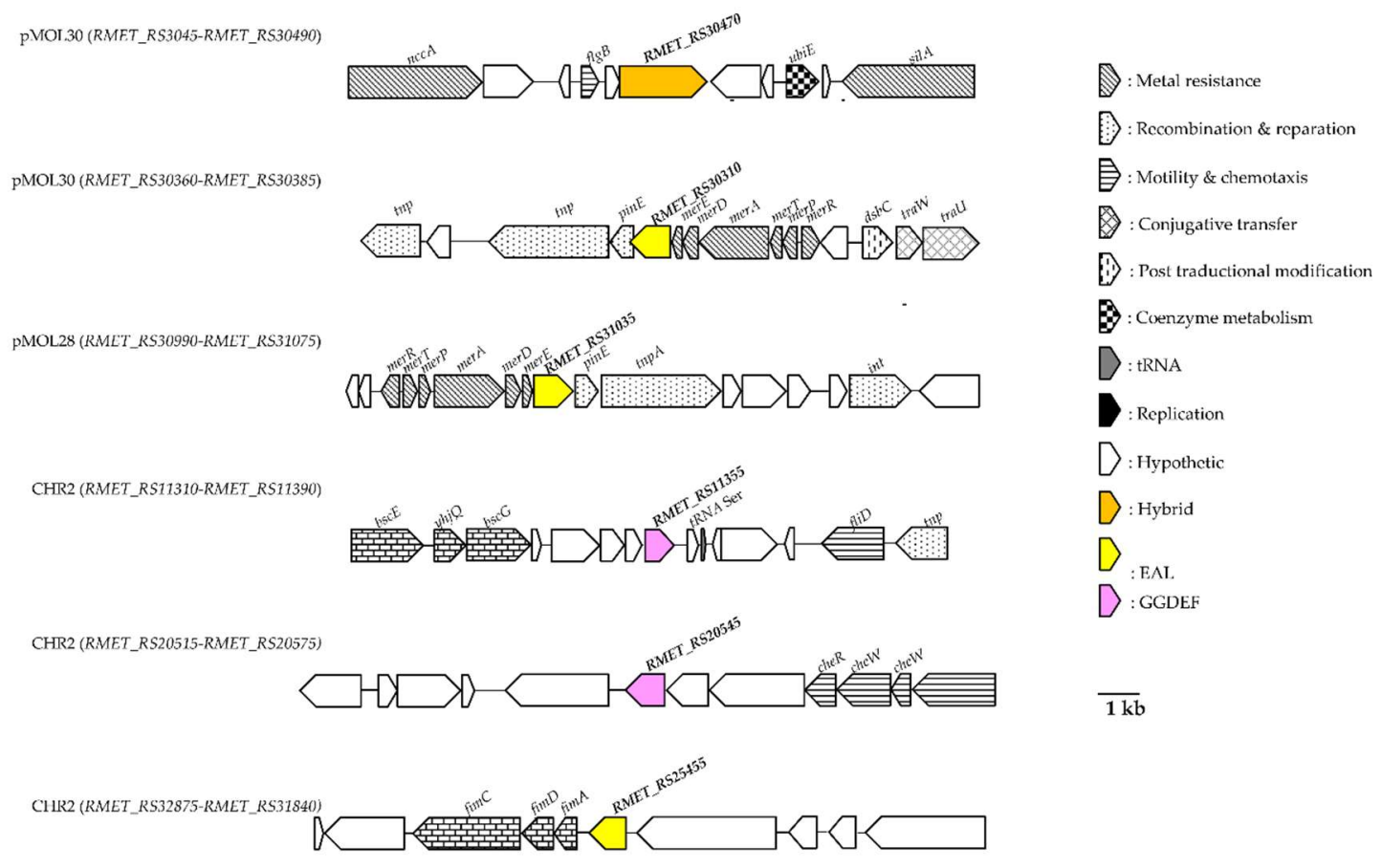

Figure S6. Genomic context of genes involved in c-di-GMP metabolism in C. metallidurans CH34. Sizes of the genes and the intergenic regions are on scale. nccA: nickel \& cobalt resistance, flgB: flagellar basal-body rod, ubiE: methyltransferase, silA: silver efflux, repA: replication protein, tnp: transposase, pinE: resolvase, merR: transcriptional regulator, merP: periplasmic mercuric-ion binding, merT: mercuric transport, merA: mercuric reductase, merD: mercuric resistance transcriptional repressor, merE: mercuric transport, urf2: unknown related function, bcsG: cellulose biosynthesis, yhjQ: cellulose synthase, bscE: cellulose production, fliD: flagellar hook cheR: methylase/chemotaxis, cheW: kinase/chemotaxis, fimA: major type 1 subunit fimbrin, fimD: outer membrane usher protein, fimC: fimbrial chaperone. Both urf2 ORFs are located between the merE gene and the transposon recombinase (PinE) coding gene of the mer operon Tn 4380 and Tn 4378 , which are located in different heavy metal resistance plasmids. The urf 2 ORF in pMOL30 overlaps with the Tn4380 resolvase ORF by 94 nucleotides. 


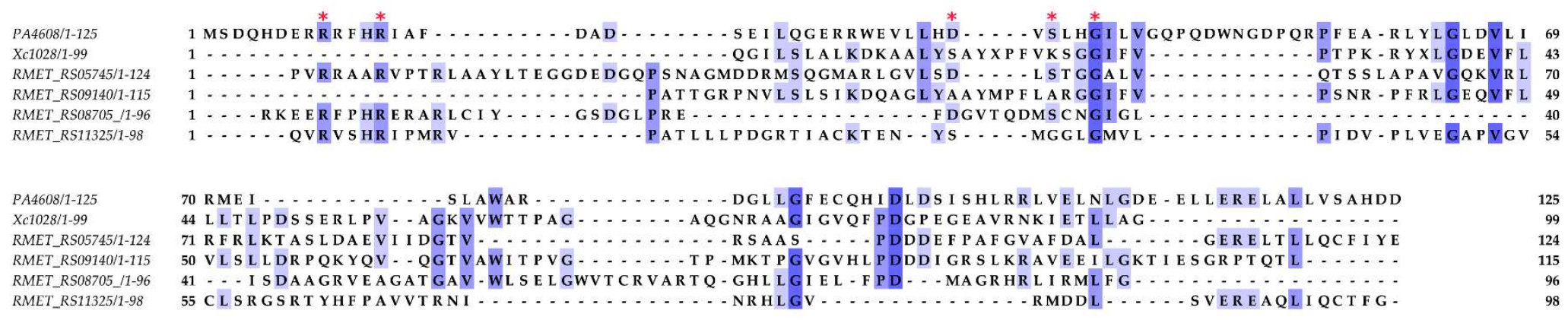

Figure S7. Multiple alignment of PilZ domains encoded in C. metallidurans CH34 genome. As references, were used the PilZ of PA4608 of $P$. aeruginosa, as active form, and the inactive form present in XC1028 of X. campestris. Symbols corresponds that comprises the "c-di-GMP swicht" binding motif. Alignments performed trough MAFFT method 


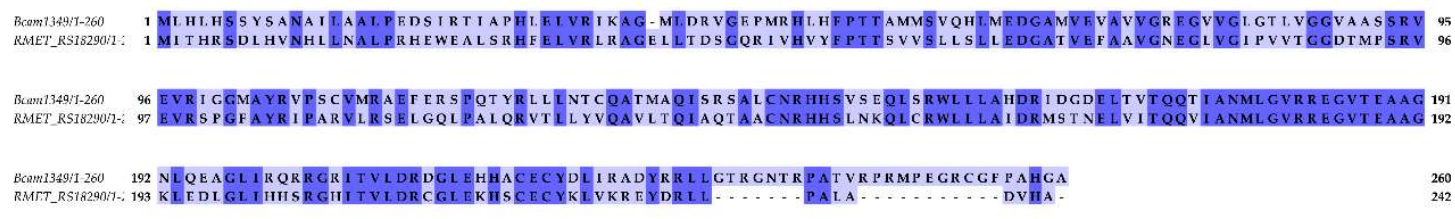

Figure S8. Global aligment between aminoacidic sequences encoded by bcam1349 (B. cenocepacia) and RMET_RS18290 (C. metallidurans CH34) genes. Sequences with $47.1 \%$ identity and $63.2 \%$ similarity. 


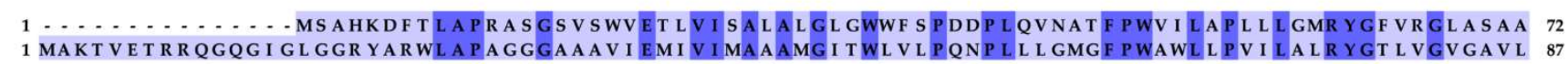
73 LLVAALFAFRVQGVEAYQVPAAFIVGVLLCAMLVGEFRDI WERRLERLELANEYRQLRLDEFTRAHHILRISHDRLEQRVAGNDQS $150^{\circ}$ 88 MLLGGWFFEDIGAHSGA-FPRMFFGGLLLLVAGQFDVWNTRLARARAVNRYLDELAALTNHYLLISHARLENDLLARTT 173

160 LRS S LLGLRQLLRELP... GDEAPLDALAETVLALLAQYGSLRIAGLYRVRYDRTPEPQPLAT LGEMPALDADDLLVRTCLERGELV 243 174 LRDTLSQLRAVAL QDAMNGGKSGPL-AGAQPMLQVVAQACQVEGAALYACDGERV-VPNAVAS IGPAFEI DVNDPLVRHCLETRALA 258 244 SVRQELLERGE QRAHSAL QVCVPLVDT DGR I LALLAVEQMPFFVFNERTF SLLAILAGHVADLLQSDRLA $\ldots \ldots \ldots \ldots \ldots$ 259 HLRST GLQQDAQTRYVAV …APVLAGS DRL I GVLVVERMPFL SLTYENL QMLMVLMGYYADGVEHARAT $\ldots \ldots \ldots \ldots \ldots \ldots$

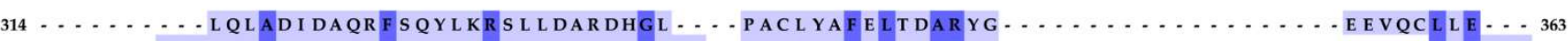

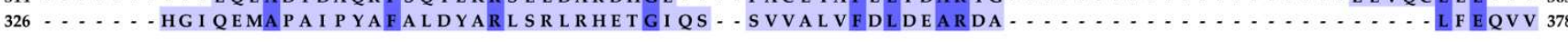

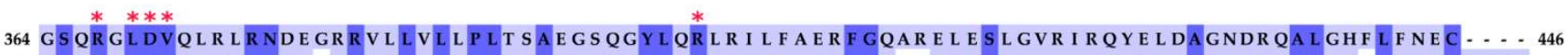

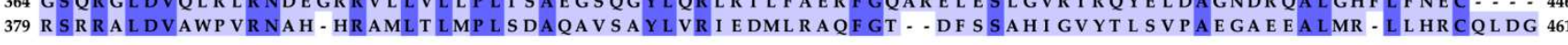
$447 \ldots . . . .$. GLNDQQVAI $\ldots . . .$. 462 AST ITAVQADGTRDASVASAGPARAG

Figura S9. Global aligment between aminoacidic sequences of c-di-GMP efector PelD encoded in genomes of P. aeruginosa PAO1 and C. metallidurans CH34. Determinant residues in c-di-GMP binding are highlighted in asterik. 
A

Planktonic

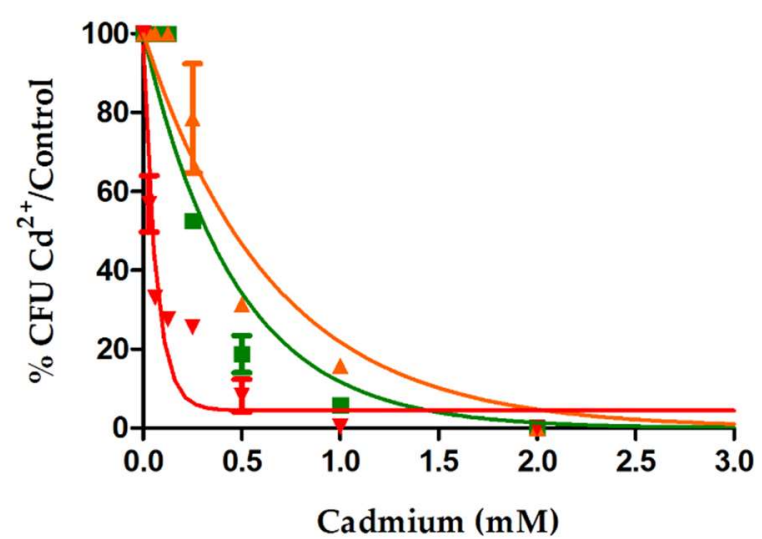

B

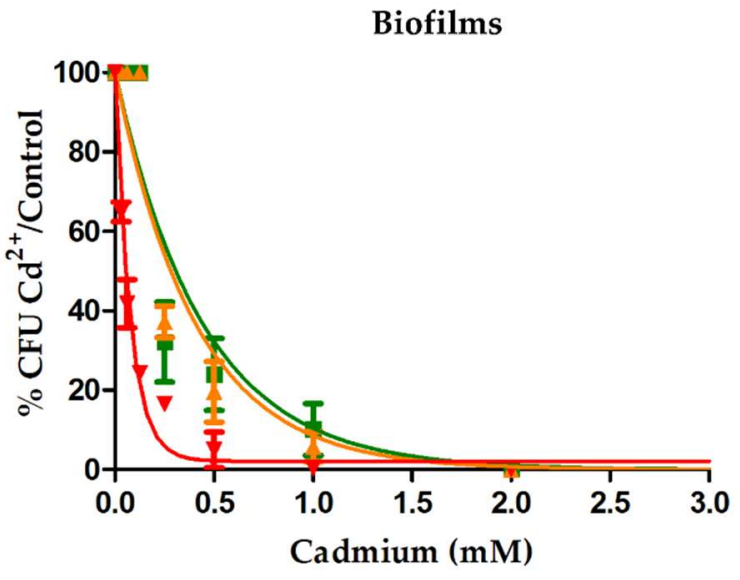

Figure S10. Cadmium kill curves of transformed strains of $C$. metallidurans $\mathrm{CH} 34$ in planktonic and biofilm lifestyles. Dots corresponds to relative viability means \pm standard deviation obtained from two biological replicates, each one by three technical replicates. Continuous lines represent non-linear regressions calculated for each strain to get susceptibility parameters (MBC \& MBEC) trough interpolation. 